Portland State University

PDXScholar

Civil and Environmental Engineering Faculty

Publications and Presentations

$1-1-2010$

\title{
Initial Expansion of the Columbia River Tidal Plume: Theory and Remote Sensing Observations
}

\author{
David A. Jay \\ Portland State University \\ Edward D. Zaron \\ Portland State University, ezaron@pdx.edu \\ Jiayi Pan \\ Portland State University
}

Follow this and additional works at: https://pdxscholar.library.pdx.edu/cengin_fac

Part of the Civil and Environmental Engineering Commons

Let us know how access to this document benefits you.

\section{Citation Details}

Jay, D. A., E. D. Zaron, and J. Pan (2010), Initial expansion of the Columbia River tidal plume: Theory and remote sensing observations, J. Geophys. Res., 115, C00B15.

This Article is brought to you for free and open access. It has been accepted for inclusion in Civil and Environmental Engineering Faculty Publications and Presentations by an authorized administrator of PDXScholar. Please contact us if we can make this document more accessible: pdxscholar@pdx.edu. 


\title{
Initial expansion of the Columbia River tidal plume: Theory and remote sensing observations
}

\author{
David A. Jay, ${ }^{1}$ Edward D. Zaron, ${ }^{1}$ and Jiayi Pan ${ }^{1,2}$ \\ Received 30 June 2008; revised 5 August 2009; accepted 16 September 2009; published 23 January 2010.
}

[1] Analysis of the Columbia River tidal plume using Lagrangian frontal equations provides a concise description of the evolution of frontal depth $H$, velocity $U$, reduced gravity $g^{\prime}$, and frontal internal Froude number $F_{R}$. Because the estuary mouth is narrow, the initial radial plume motion is supercritical $\left(F_{R}>1\right)$ for up to 12 hours. Understanding this supercritical phase is vital, because plume properties change rapidly, with strong ecosystem impacts. To analyze this expansion, analytical and numerical models (the latter with three mixing formulations) were tested. Model results are compared to synthetic aperture radar images to verify that the predicted frontal properties are realistic.

Lagrangian theory provides especially simple constraints (independent of the mixing model) on spatial variations in $F_{R}$ and $U g^{\prime} H$. For parameters representative of the Columbia River plume, the plume spreads $10-35 \mathrm{~km}$ and thins to $25-60 \%$ of its initial depth before becoming subcritical. After liftoff, $F_{R}$ increases as the front accelerates and thins, it then decreases to unity; $g^{\prime}$ decreases, but more slowly than $H$ and $U . H$, controlled by a balance between spreading and mixing, first decreases then increases. The strength of vertical mixing and the mixing efficiency $E_{F}$ (ratio of buoyancy flux to dissipation) both play a significant role in determining plume properties, and it is important to include both the horizontal gradient in $g^{\prime}$ and surface slope component of the pressure gradient. A model with an Ellison-Turner type entrainment scheme predicts the plume trajectory better than one that assumes a constant interfacial gradient Richardson number.

Citation: Jay, D. A., E. D. Zaron, and J. Pan (2010), Initial expansion of the Columbia River tidal plume: Theory and remote sensing observations, J. Geophys. Res., 115, C00B15, doi:10.1029/2008JC004996.

\section{Introduction}

\subsection{Scope}

[2] This paper provides a dynamical analysis of the Columbia River "tidal plume" as it emerges from the mouth of the Columbia River (MCR). Flow through the MCR is tidally pulsed. The tidal plume is the new water mass entering the ocean on each ebb [Horner-Devine et al., 2009]. The extent of the tidal plume is defined by its outer boundary front, whose nearly circular shape is often visible in synthetic aperture radar (SAR) images (Figure 1 and Table 1) [Pan et al., 2007]. The tidal plume remains supercritical (with respect to the frontal internal Froude number $F_{R}$ ) and distinct from the remainder of the plume near-field (which consists of water that has emerged from the estuary over several tidal cycles) for up to 12 hours, after which time it becomes subcritical $\left(F_{R}<1\right)$ and mixes into the plume near-field. The transition to subcritical conditions is often accompanied by emission of a train of

\footnotetext{
${ }^{1}$ Department of Civil and Environmental Engineering, Portland State University, Portland, Oregon, USA.

${ }^{2}$ Institute of Space and Earth Information Science, Chinese University of Hong Kong, Shatin, Hong Kong.

Copyright 2010 by the American Geophysical Union. 0148-0227/10/2008JC004996\$09.00
}

large-amplitude, nonlinear internal waves (Figure 2) [Pan et al., 2007; Nash and Moum, 2005] that take most of the energy out of the front [Pan and Jay, 2009]. The effects of mixing that occurs in the early hours of tidal plume motion endure well after the transition to subcritical conditions. We use here Lagrangian frontal equations [Rudnick and Davis, 1988] to investigate this initial plume radial expansion and the following transition to subcritical flow.

[3] The initial, almost radial, motion of a tidal plume emerging from an estuary mouth poses an intriguing dynamical problem. For a narrow estuarine mouth like the MCR, the front is supercritical $\left(F_{R}>1\right)$ from the point of plume liftoff, due to a combination of tidal and buoyancy forcing. This supercritical, radial expansion shows a superficial resemblance to small-scale thermal plumes and river plumes from small river mouths. However, the MCR outflow is tidally pulsed, changing the structure of the plume near-field [Horner-Devine et al., 2009]. Also, the size of the fully developed tidal plume (typically $10-30 \mathrm{~km}$ ) is such that rotation, though not dominant, cannot be altogether ignored, conservation of potential vorticity requires that changes in plume thickness be compensated by changes in total vorticity that are a function of plume radius $R$ [Horner-Devine, 2009].

[4] The rapid changes that occur in the tidal plume are also vital to the plume ecosystem [Hickey et al., 2009]. 
01-13-2002 01:54 T=6.2 hrs $R=18.4 \mathrm{~km}(U)$

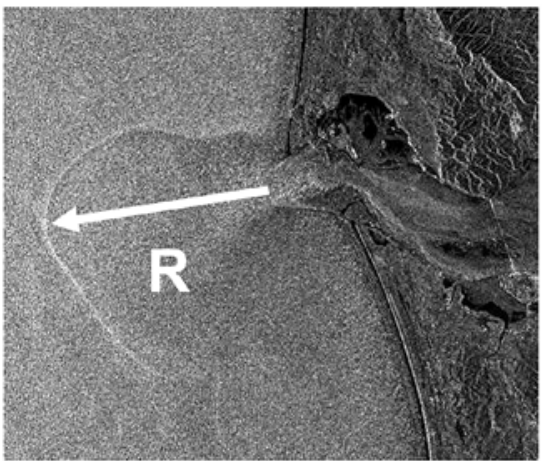

06-29-2002 14:39 T=3.8 hrs $R=10.2$ km (D)

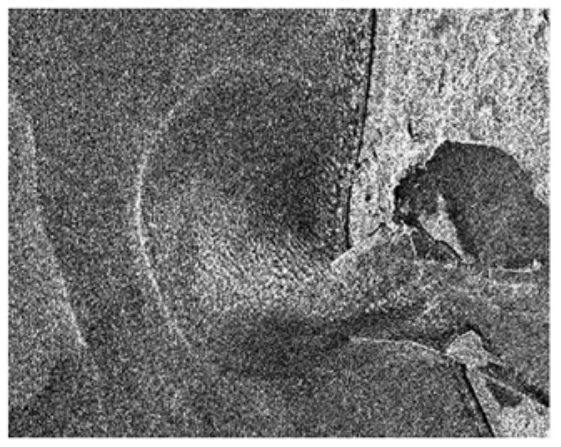

03-10-2003 14:39 T=2.2 hrs $R=6.2$ km (D)

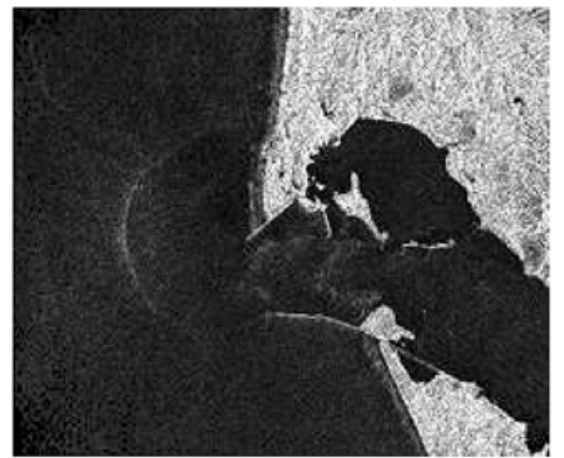

01-30-2002 01:54 T=5.3 hrs $R=16.0 \mathrm{~km}(\mathrm{~N})$

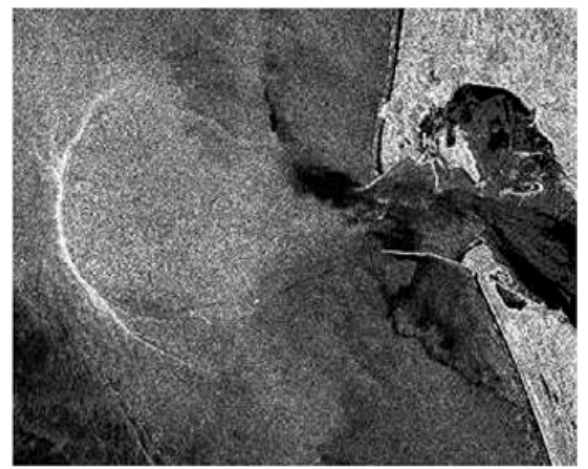

01-01-2003 01:54 T=7.9 hrs $R=21.3 \mathrm{~km}(\mathrm{~N})$

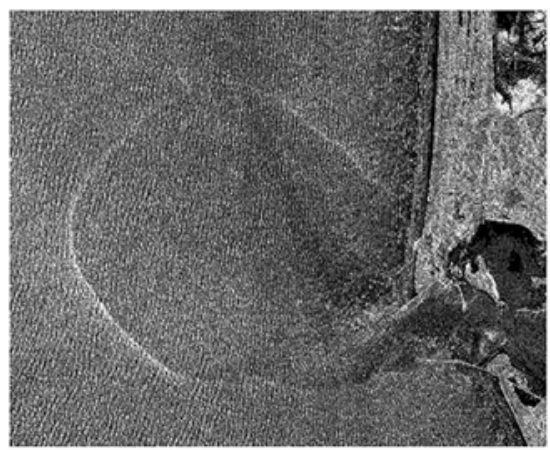

08-18-2003 14:39 T=2.0 hrs R=5.4 km (U)

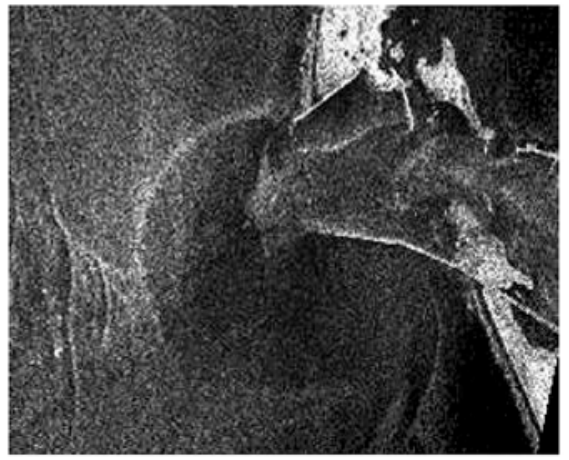

Figure 1. SAR images of the tidal plume, which is almost radially symmetric under a wide variety of upwelling (U), downwelling (D), and neutral $(\mathrm{N})$ forcing conditions. $R$ is the estimated frontal travel distance from the end of the jetties for each image. Tidal ranges are listed in Table 1. Images were selected to show fronts that were supercritical along at least part of their length.

Orton and Jay [2005] estimated $\sim 20 \%$ of the vertical mixing needed to increase plume salinity from 15 to 33.5 could be accounted for by mixing at and near the front ( $\sim 2 \%$ of tidal plume area), with more occurring in the interior of the tidal plume. Pan and Jay [2009] have shown that nonlinear, plume-front-generated internal waves transfer mass and energy offshore, facilitating horizontal and vertical mixing, and extending the influence of the tidal plume to a considerable area beyond its bounding front. Vertical mixing associated with tidal plume fronts and internal waves may also facilitate primary productivity in the plume area [Jay et al., 2009], and preferential occur- rence of strong fronts and internal waves north of the estuary mouth may be one factor leading to elevated productivity on the Washington shelf relative to the Oregon shelf.

[5] Several aspects of plume and frontal dynamics are challenging to represent in numerical and analytical models. The tidal plume front is nonhydrostatic, because of the steep interfacial slope in the vicinity of the plume bulge, and generates nonlinear internal waves as it decays to a subcritical state [Jay et al., 2009; Pan and Jay, 2009]. Furthermore, the dimensions of the supercritical plume front, 5$10 \mathrm{~m}$ deep and $20-50 \mathrm{~m}$ laterally, means that it is very 
Table 1. Plume Frontal Radius $R$ and Travel Time $T(R)$ From SAR Images and Ambient Coastal Conditions

\begin{tabular}{|c|c|c|}
\hline$\underline{\text { SAR Image Date/Time }}{ }^{a}$ & $R(\mathrm{~km})$ & $T(R)$ (hours) \\
\hline \multicolumn{3}{|c|}{ Upwelling } \\
\hline $02-24-2001 / 0216$ & 12.8 & 5.6 \\
\hline $10-01-2001 / 1438$ & 16.6 & 7.1 \\
\hline $11-02-2001 / 0155$ & 12.6 & 5.6 \\
\hline $01-13-2002 / 0154$ & 18.4 & 6.2 \\
\hline $05-06-2002 / 0154$ & 20.1 & 10.9 \\
\hline $06-05-2002 / 1439$ & 30.0 & 10.2 \\
\hline $07-13-2002 / 1439$ & 10.4 & 4.7 \\
\hline $07-23-2002 / 1439$ & 22.3 & 7.7 \\
\hline $07-24-2002 / 0154$ & 11.2 & 5.3 \\
\hline $08-09-2002 / 1439$ & 17.0 & 6.4 \\
\hline $10-04-2002 / 0154$ & 17.1 & 7.4 \\
\hline $10-17-2002 / 1439$ & 17.3 & 9.1 \\
\hline $06-01-2003 / 1439$ & 8.1 & 6.2 \\
\hline $06-24-2003 / 1439$ & 24.3 & 11.0 \\
\hline $07-01-2003 / 1439$ & 13.3 & 5.9 \\
\hline $07-25-2003 / 1439$ & 24.0 & 9.8 \\
\hline $08-12-2003 / 0154$ & 10.0 & 5.2 \\
\hline $08-18-2003 / 1439$ & 5.4 & 2.0 \\
\hline $08-28-2003 / 1439$ & 18.5 & 6.2 \\
\hline $09-21-2003 / 1439$ & 23.0 & 11.2 \\
\hline \multicolumn{3}{|c|}{ Downwelling } \\
\hline $05-07-2001 / 0216$ & 15.5 & 6.2 \\
\hline $12-16-2001 / 0212$ & 13.5 & 5.9 \\
\hline $05-26-2002 / 0439$ & 19.7 & 7.0 \\
\hline $05-29-2002 / 1439$ & 14.6 & 5.0 \\
\hline $01-01-2003 / 0154$ & 21.3 & 7.9 \\
\hline $02-01-2003 / 0154$ & 18.4 & 6.4 \\
\hline $03-10-2003 / 1439$ & 6.2 & 2.2 \\
\hline $03-14-2003 / 0154$ & 19.4 & 10.2 \\
\hline $03-20-2003 / 1439$ & 9.8 & 4.9 \\
\hline $06-14-2003 / 1439$ & 20.3 & 7.2 \\
\hline $07-11-2003 / 1439$ & 22.3 & 9.2 \\
\hline $08-25-2003 / 1439$ & 16.1 & 8.6 \\
\hline $09-28-2003 / 1439$ & 6.9 & 4.7 \\
\hline \multicolumn{3}{|c|}{ Neutral } \\
\hline $03-20-2001 / 0216$ & 18.7 & 9.9 \\
\hline $09-28-2001 / 1426$ & 22.8 & 9.3 \\
\hline $11-26-2001 / 0155$ & 24.5 & 9.1 \\
\hline $01-30-2002 / 0154$ & 16.0 & 5.3 \\
\hline $03-26-2002 / 0154$ & 20.6 & 8.4 \\
\hline $04-12-2002 / 0154$ & 15.1 & 5.8 \\
\hline $06-23-2002 / 0154$ & 20.0 & 6.8 \\
\hline $06-29-2002 / 1439$ & 10.2 & 3.8 \\
\hline $07-16-2002 / 1439$ & 8.5 & 1.7 \\
\hline $10-03-2002 / 1439$ & 19.4 & 9.6 \\
\hline $10-04-2002 / 0154$ & 16.2 & 7.4 \\
\hline $11-13-2002 / 1439$ & 31.3 & 12.0 \\
\hline $11-20-2002 / 1439$ & 11.5 & 5.6 \\
\hline $12-31-2002 / 1439$ & 19.2 & 8.0 \\
\hline $02-18-2003 / 0154$ & 13.4 & 5.2 \\
\hline $04-20-2003 / 1439$ & 9.7 & 4.2 \\
\hline $04-30-2003 / 1439$ & 20.7 & 6.9 \\
\hline $05-14-2003 / 1439$ & 18.2 & 8.1 \\
\hline $05-21-2003 / 1439$ & 7.2 & 2.8 \\
\hline $05-24-2003 / 1439$ & 29.3 & 10.8 \\
\hline $05-25-2003 / 0154$ & 25.5 & 10.4 \\
\hline $05-31-2003 / 1439$ & 21.1 & 6.7 \\
\hline $06-01-2003 / 0154$ & 7.5 & 4.3 \\
\hline
\end{tabular}

${ }^{a}$ Date/time format used here is month-day-year/hour.

difficult to represent in a mesoscale, 3-D numerical model. We have, therefore, used a combination of layered analytical and numerical models and remote sensing to analyze the tidal plume. Lagrangian frontal equations [Rudnick and Davis, 1988] are attractive for this modeling, because of their ability to represent frontal processes in a model of reduced dimensionality (vertically layered and 1-D radially symmetric in the horizontal). Because the lower layer is motionless, our approach is effectively a 1.5 layer model in the sense of Røed [1997].

\subsection{Regional Setting}

[6] The Columbia is the fourth largest river entering the ocean from North America, with an average flow of $\sim 7300 \mathrm{~m}^{3} \mathrm{~s}^{-1}$ [Bottom et al., 2005]. A typical minimum (fall) flow is $2000-3000 \mathrm{~m}^{3} \mathrm{~s}^{-1}$, while the spring freshet flow is usually $10,000-15,000 \mathrm{~m}^{3} \mathrm{~s}^{-1}$. Although the spring freshet volume has been reduced by $40-45 \%$ by human intervention, the Columbia plume still plays a major role in coastal circulation and ecosystem processes and in the greater northeast Pacific [Barnes et al., 1972; Hickey et al., 1998; Thomas and Weatherbee, 2006]. The plume also plays a vital role in the survival of juvenile Columbia River salmonids, several races of which are classified as endangered [Gustafson et al., 2007].

[7] The high river outflow from the Columbia causes the plume to be very stratified. The shelf is also relatively steep, with a slope of $\sim 8 \times 10^{-4}$. Away from the MCR, typical plume depths are 3-7 $\mathrm{m}$ in a water column 30-200 $\mathrm{m}$ deep, and the plume affects the bed only immediately beneath plume fronts and near liftoff [Orton and Jay, 2005; Spahn et al., 2009]. Thus, the Columbia plume is "surface advected" in the sense of Yankovsky and Chapman [1997], and our models neglect internal hydraulic interactions of the plume front with the seabed, after the initial liftoff.

[8] The Columbia plume far-field assumes diverse configurations [Hickey et al., 2005] and varies on coastal weather time scales. Winds and coastal currents strongly influence the plume's far-field behavior and the variable salinity of the nearshore waters with which the tidal plume interacts. Still, the initial motion of the tidal plume is relatively consistent and determined primarily by river outflow and tidal forcing. Thus, this analysis focuses on the impacts of these two factors, which together determine the initial $F_{R}$ number, rather than on the effects of atmospheric forcing. The MCR tidal regime is mixed semidiurnal and diurnal, with the semidiurnal species being dominant. The tidal range varies from $\sim 1 \mathrm{~m}$ on a weak lesser ebb to $4 \mathrm{~m}$ on the largest greater ebbs. Peak ebb currents in the MCR entrance are very strong $\left(1-3.5 \mathrm{~m} \mathrm{~s}^{-1}\right)$, due to the narrow entrance $(\sim 3 \mathrm{~km})$; these strong currents drive the initial supercritical motion.

\subsection{Previous Analyses of Plume Motion}

[9] The importance of buoyant plumes as a fluid dynamics problem with numerous applications has resulted in a considerable literature. Chu and Baddour [1984] and Chu and Jirka [1986] summarize scaling laws and similarity solutions for steady state plumes. Observations of small, quasi-steady plumes in nature [e.g., Ingram, 1981; Luketina and Imberger, 1987] are well described by these scalings. Studies of plume and gravity current frontal propagation have emphasized the importance of mixing. Laboratory studies find that the front propagates so as to maintain an almost constant bulk Froude number [Benjamin, 1968; Britter and Simpson, 1978]. Mixing must, therefore, play a major role in the determining propagation speed, because a constant $F_{R}$ plume does not conserve energy [Garvine, 1982]. Observations by Garvine and Monk [1974], Luketina 


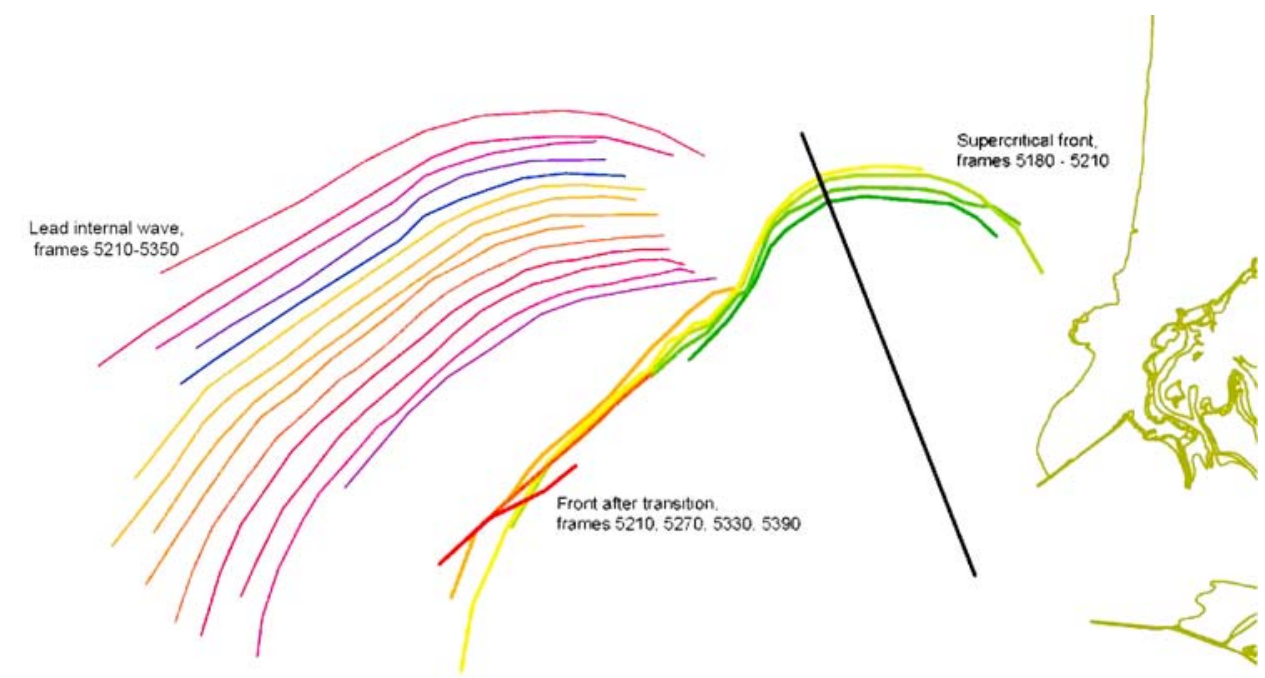

Figure 2. Tidal plume frontal position and the position of the lead internal soliton generated by the front, determined from ship's radar on 9 June 2006 starting at 0119 UT. Images were acquired at one frame per minute and every 10th frame was processed. Frame time is coded by shade. Frontal advance rate was determined from the portion of the front that was supercritical, along the black line.

and Imberger [1989], O'Donnell et al. [1998, 2008], MacDonald and Geyer [2004], Hetland and MacDonald [2008], and Orton and Jay [2005] suggest that mixing and entrainment at the leading edge of buoyant plumes is substantial, but largely confined to a zone (which may be several $\mathrm{km}$ in extent) at and behind the plume front. Additional mixing occurs near liftoff [Nash et al., 2009].

[10] Plume models have sought to explain the threedimensional circulation and mixing near the plume front, and they have indicated that flow at the front influences the dynamics of the plume interior, well behind the front [Garvine, 1982, 1987]. This influence is caused by the propagation of information along characteristics from the plume front into the interior of the plume. O'Donnell [1990] extended these modeling efforts to include interfacial drag and entrainment in addition to the (dissipative) plume jump conditions which had previously been used. The results indicate that large portions of the plume will be subject to shear-driven instability and interfacial mixing, as indicated by the presence of extensive regions of elevated bulk Froude number. O'Donnell [1990] focuses on the response of the plume to along-shore ambient flow, noting that interfacial mixing is most important when the along-shore flow is weak. These results suggest that our analysis, which describes the tidal plume in terms of the properties of its bounding front, is dynamically appropriate. Questions remain, however, regarding sensitivity to the precise form of the mixing parameterization, and energetic consequences of the interfacial mixing for the plume as a whole. Results below indicate that both the turbulence closure and details of the assumed dynamics influence plume propagation.

[11] Recent work has explored how plume dynamics and frontal processes are modified by rotation, and motion of the ambient flow [Fong and Geyer, 2002; Horner-Devine, 2009; Hetland, 2005]. Pritchard and Huntley [2006] used observations and a continuity constraint to estimate the ratio of vertical buoyancy flux to buoyancy input from the riverine source. In their terms, the Columbia plume has sufficient buoyancy to form a plume on all ebbs. Hetland [2005] used an isopycnal coordinate system to investigate plume mixing, an approach with some similarities to this Lagrangian analysis. Nash et al. [2009] analyze plume properties at and near the liftoff point, early in the period modeled here. They find that (1) initial plume salinity and thickness depend on the cumulative mixing that has occurred in the estuary upstream of liftoff and (2) interfacial mixing at the plume base depends on the strength of the tidal pulse; i.e., on the shear and stratification at the base of the plume. Pan et al. [2007] and Pan and Jay [2009] investigated frontal fission and the resultant internal wave generation and propagation. Here our goals are to investigate the behavior of the plume between the source region and the point of frontal collapse (transition to $F_{R}<1$ ), and to refine previous models based on the assumption of constant $F_{R}$ at the plume front.

\section{Methods: Model Formulation}

\subsection{A Lagrangian Approach}

[12] Jay et al. [2009] argue that (1) the Columbia tidal plume is nearly circular; (2) plume expansion continues after the reversal of tidal currents at the end of ebb, for up to 12 hours; (3) front-normal velocities are considerably larger than along-frontal velocities; and (4) the vorticity of the underlying tidal flow only subtly alters plume frontal properties, introducing small along-frontal asymmetries. The tidal plume is initially $8-12 \mathrm{~m}$ thick, but only $3-7 \mathrm{~m}$ thick during the latter part of its expansion [Cudaback and Jay, 1996, 2000; Jay et al., 2009]. These factors together imply that, except in and near the liftoff zone, the plume front is only weakly coupled to the underlying tidal flow. Also implied is that the lowest-order radial expansion is a function of frontal radius $R$ only. Thus, we consider here the dynamics of an initial, almost radial, expansion of a tidal plume away from the MCR. 


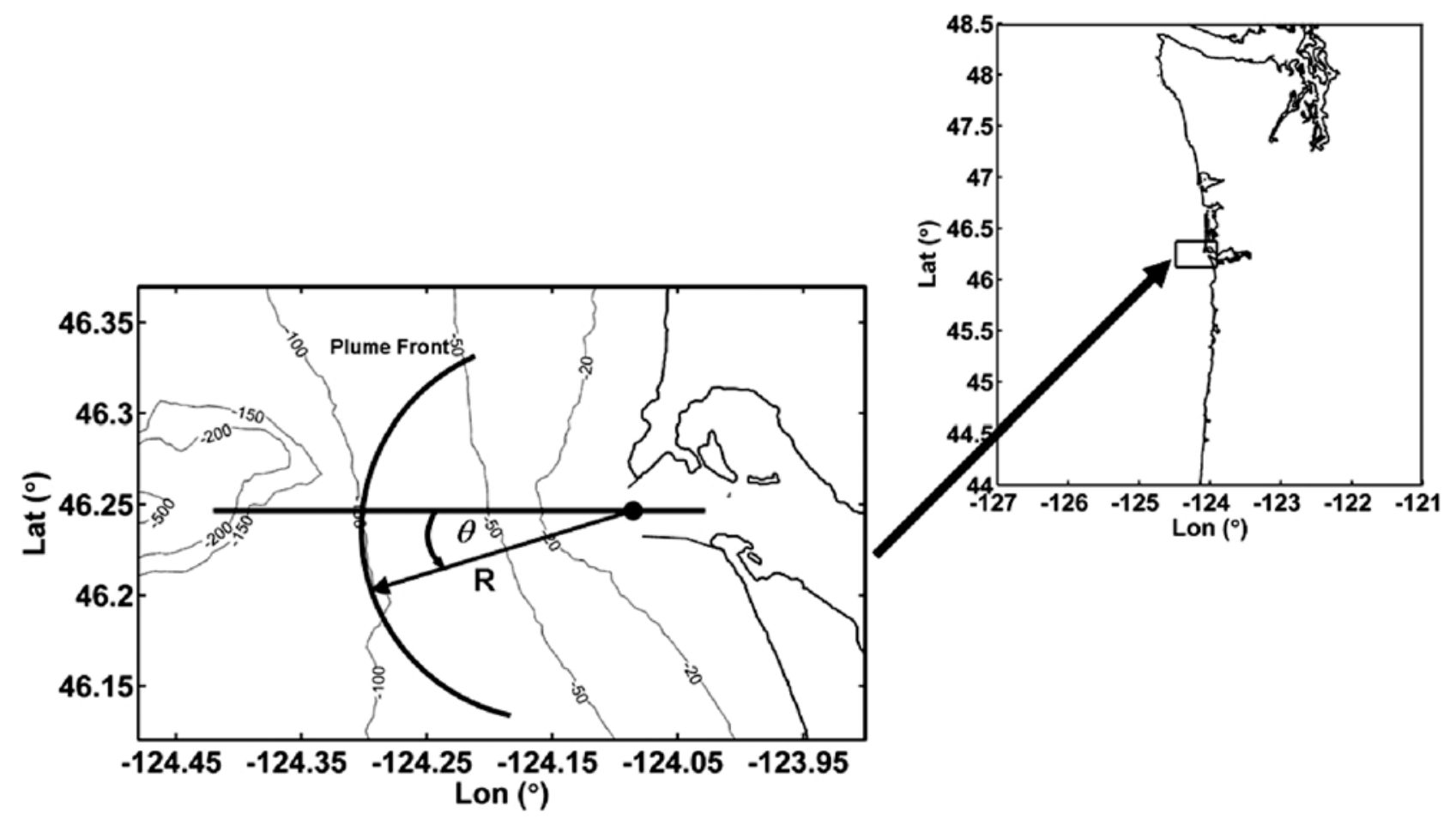

Figure 3. Regional plume context and coordinate system.

[13] The tidal plume and its bounding front can, given the above properties, be described to lowest order by four frontal variables: depth $H$, speed $U$, reduced gravity $g^{\prime}$, and Froude number $F_{R}=\frac{U}{\sqrt{g^{\prime} H}}$. These variables are Lagrangian, they are defined only at the front, as a function of frontal radius, $R$. Further, if the estuary entrance is narrow with Kelvin number $K=B / R_{O} \ll 1$, the initial outflow can be treated as spreading radially from a point at the estuary entrance, as given by Hetland and MacDonald [2008]. (Here, $B$ is entrance width, $R_{O}=\frac{\left(g_{0}^{\prime} H_{0}\right)^{\frac{1}{2}}}{f}$ is the internal Rossby number, $f$ is the Coriolis parameter, and $g_{0}^{\prime}$ and $H_{0}$ are reduced gravity and plume layer depth at the entrance, respectively.) Although the tidal plume does begin to rotate as it thins and its front slows, plume rotation (azimuthal flow) remains a secondary process for a supercritical tidal plume. Formally, azimuthal flow cannot be larger than $\mathrm{O}\left(\varepsilon_{F}\right)$, where $\varepsilon_{F}$ is a small parameter to be defined.

[14] The frontal properties $H, F_{R}, U$, and $g^{\prime}$ can be quantified using Lagrangian frontal equations [Rudnick and Davis, 1988]. Because the initial supercritical motion is nearly radial, these equations are applied in a cylindrical coordinate system; $R$ is the distance offshore from the estuary mouth and $\mathrm{q}$ is the angle of rotation (Figure 3). This analysis considers, as noted, only the initial supercritical $\left(F_{R}>1\right)$, plume expansion. The equations can be solved for subcritical conditions, but atmospheric forcing and shelf flows (not considered here) play a much larger role as the tidal plume merges into the larger plume near-field. Also, we do not consider here the complex dynamics of the plume front "plunge" (modeled by Garvine [1981, 1982]). Just as hydraulic control theory defines the conditions under which a turbulent hydraulic jump occurs, this analysis defines the location and energetics of the plume front without specify- ing the details of actual frontal structure in which energy is dissipated. Thus, $H, F_{R}, U$, and $g^{\prime}$ describe plume properties just behind the plunge, and the mixing formulation included in the model should describe the mixing of the shear layer just behind the actual front.

[15] One advantage of a Lagrangian approach is that the expressions for mass deficit and freshwater fraction are relatively simple. Also, the convective accelerations, important in an Eulerian treatment of supercritical flow, are included in the total acceleration. There are two disadvantages. First, the plume flow is defined only at the front, as a function of the sole independent variable, radius $R$. The second issue derives from the first, the time $T$ at which the front reaches a particular radius is not an independent variable, and $T(R)$ must be derived as part of the solution.

\subsection{Plume Frontal Equations}

[16] Describing the tidal plume in terms of frontal properties implies the use of Lagrangian variables. Here, we define the governing equations for mass, density and momentum conservation using the following nondimensional Lagrangian variables:

$$
\begin{aligned}
& \hat{H}=H_{0} H(R) \quad \hat{U}=U_{0} U(R) \quad \hat{V}=\varepsilon_{F} U_{0} V(R) \\
& \hat{g}^{\prime}=g_{0}^{\prime} g^{\prime}(R) \quad \hat{g}^{\prime}=g \frac{\Delta \hat{\rho}}{\hat{\rho}_{0}} \quad \varepsilon_{F}=1-\frac{H_{T R}}{H_{0}} \\
& \hat{F}_{R}^{2}=F_{R 0}^{2} \frac{U^{2}}{g^{\prime} H} \quad F_{R 0}^{2}=\frac{U_{0}^{2}}{g_{0}^{\prime} H_{0}},
\end{aligned}
$$

where $g$ is gravitational acceleration, $\Delta \hat{\rho}$ is the plume density difference relative to lower layer (reference) density, 
$\rho_{0}$ is reference density, $H_{T R}$ is a scale for plume depth at the point of transition to subcritical conditions $\left(F_{R}<1\right), H_{0}, U_{0}$, $R_{0}$, and $g_{0}^{\prime}$ are the dimensional scales for plume front thickness, velocity, radius, and reduced gravity, respectively, and the carat $\wedge$ indicates a dimensional variable. $H_{0}$, $U_{0}$, and $g_{0}^{\prime}$ are all defined using initial values at liftoff. $R_{0}$ is the radius at which the front becomes subcritical. The small parameter $\varepsilon_{\mathrm{F}}$ does not actually enter the analysis, but processes neglected (e.g., rotation) cannot be larger than $O\left(\varepsilon_{\mathrm{F}}\right)$. The definition of $\varepsilon_{\mathrm{F}}$ in (1a) implies that plume rotation $(\hat{V})$ occurs in proportion to plume thinning.

[17] Conservation of mass (water) describes the evolution of frontal depth $H$ as the front undergoes radial spreading and mixing. In cylindrical coordinates and dimensional variables, the expression of Rudnick and Davis [1988] is

$$
\frac{D \hat{H}}{D \hat{t}}=-\hat{H}\left(\frac{\partial \hat{U}}{\partial \hat{R}}+\frac{\hat{U}}{\hat{R}}+\frac{1}{\hat{R}} \frac{\partial \hat{V}}{\partial \hat{\theta}}\right)+\hat{W}_{E},
$$

where $\hat{W}_{E}>0$ is a vertical entrainment velocity. From (2), we see that changes in $\hat{H}$ following the front are controlled by a balance between plume spreading, which thins the plume, and turbulent entrainment of ambient waters (as specified by $\hat{W}_{E}$ ), which thickens it.

[18] The total derivative in (2) describes the Lagrangian evolution of the flow. We now use the definitions in (1a) and (1b) to express this total derivative in another form. This is clearest in nondimensional variables; to lowest order we write in cylindrical coordinates

$$
\frac{D}{D t}=\frac{\partial}{\partial t}+U \frac{\partial}{\partial R}+\frac{\varepsilon_{F}}{R} V \frac{\partial}{\partial \theta} \cong U \frac{\partial}{\partial R}+O\left(\varepsilon_{F}\right) .
$$

[19] The local time derivative vanishes, because all frontal variables are functions of $R$ only. $\hat{H}$ and other frontal variables are not functions of $\hat{t}$ (with $\hat{R}$ constant), because they are not field variables. The form of the total derivative in (3a) may be explained in another way. By definition, $\hat{U}$ is the rate at with frontal radius $\hat{R}$ changes, $\frac{d \hat{R}}{d \hat{t}}$; thus (using $\hat{H}(\hat{R})$ as an example)

$$
\frac{D \hat{H}}{D \hat{t}}=\frac{d \hat{H}}{d \hat{R}} \frac{d \hat{R}}{d \hat{t}}=\frac{d \hat{H}}{d \hat{R}} \hat{U} \quad \hat{U} \equiv \frac{d \hat{R}}{d \hat{t}},
$$

because $\hat{H}$ is a function of $(\hat{R})$ only. Therefore, (2) with (3b) may be written in nondimensional form, using a parameterization of entrainment velocity $\hat{W}_{E}$; to lowest order

$$
\begin{aligned}
\frac{d H}{d R} \cong-\frac{H}{U}\left(\frac{d U}{d R}+\frac{U}{R}\right)+\gamma_{1} \Gamma_{1} \\
\hat{W}_{E}=C_{1} \Gamma_{1}(\hat{R}) \hat{U} \quad \gamma_{1}=\frac{C_{1} R_{0}}{H_{0}}
\end{aligned}
$$

where $\hat{W}_{E}=C_{1} \Gamma_{1}(R) \hat{U}$ is a spatially variable entrainment velocity, $C_{1}$ is an entrainment coefficient, and $\Gamma_{1}(R)$ describes the spatial variability of the strength of entrainment. The boundary condition on $H(R)$ is

$$
H\left(R_{00}\right)=1 .
$$

[20] The boundary condition is set at $\hat{R}=\frac{B_{0}}{2}$ (i.e., at half the entrance width $B_{0}$, where $R=R_{00}$ ) in recognition of the finite entrance width, and to avoid dealing with a singularity at $\hat{R}=0$. It is then useful to write (4) as

$$
\frac{d \ln (U H)}{d R}=-\frac{1}{R}+\frac{\gamma_{1} \Gamma_{1}}{H},
$$

where $\ln ()$ is the natural logarithm. From (6), it is evident that frontal water transport $U H$ decreases through radial expansion and increases due to entrainment.

[21] Momentum conservation in the radial direction may also be treated in a vertically averaged, Lagrangian form; in dimensional variables we have

$$
\begin{aligned}
\frac{D \hat{U}}{D \hat{t}} & \cong \hat{U} \frac{d \hat{U}}{d \hat{R}}=-\left(\frac{1}{\rho_{0}} \frac{1}{\hat{H}} \int_{-\hat{h}}^{\hat{\zeta}} \frac{d \hat{p}}{d \hat{R}} d \hat{z}+\frac{\hat{\tau}_{I}}{\hat{H}}\right) \\
& \approx-\left(\frac{1}{2 \hat{H}} \frac{d}{d \hat{R}}\left(\hat{g}^{\prime} \hat{H}^{2}\right)+\frac{C_{2} \Gamma_{2}}{\hat{H}} \hat{U}^{2}\right), \\
\hat{\tau}_{I} & =C_{2} \Gamma_{2}(\hat{R}) \hat{U}_{F}^{2}
\end{aligned}
$$

with the pressure gradient given by

$$
-\frac{1}{\rho_{0}} \frac{1}{\hat{H}} \int_{-\hat{h}}^{\hat{\zeta}} \frac{d \hat{p}}{d \hat{R}} d \hat{z} \cong-\frac{1}{2 \hat{H}} \frac{d}{d \hat{R}}\left(\hat{g}^{\prime} \hat{H}^{2}\right)=-\frac{d\left(\hat{g}^{\prime} \hat{H}\right)}{d \hat{R}}-\frac{\hat{H}}{2} \frac{d \hat{g}^{\prime}}{d \hat{R}},
$$

where $\hat{p}$ is pressure, $\hat{H}=\hat{h}+\hat{\varsigma}$ is the sum of surface displacement $\hat{\varsigma}$ and plume basal depth $\hat{h}, C_{2} \Gamma_{2}(R) \hat{U}^{2}$ is a representation of the spatially variable interfacial stress $\hat{\tau}_{I}$, $C_{2}$ is a constant, and $\Gamma_{2}(R)$ describes the spatial variability of vertical turbulent momentum transfer. Specifically, $\hat{\tau}_{I}$ is the stress on the plume by a hypothetical motionless layer beneath the plume. This neglects the stress on the plume associated with the tidal motion of the subsurface layer; but this stress is, by assumption, no larger than $O\left(\varepsilon_{F}\right)$ and is not relevant here.

[22] The assumption of isostatic adjustment (7b) is common in theoretical analyses of buoyant plumes [e.g., Garvine, 1982, 1987]. However, following Røed [1997] we include here the effects on the pressure gradient (in both the surface slope and baroclinic integral) of the spatial variations in $\mathrm{g}^{\prime}$; these terms are often neglected in analytical plume theories but included in numerical models [e.g., O'Donnell, 1990]. Then (7a) and (7b) may be written in nondimensional form as

$$
\begin{gathered}
\frac{d \ln U}{d R}=-\left(\frac{1}{F_{R}^{2}} \frac{1}{g^{\prime} H}\left(\frac{d\left(g^{\prime} H\right)}{d R}+\frac{H}{2} \frac{d g^{\prime}}{d R}\right)+\frac{\gamma_{2} \Gamma_{2}}{H}\right) \\
\gamma_{2}=\frac{C_{2} R_{0}}{H_{0}}
\end{gathered}
$$

The boundary condition on $U$ is

$$
U\left(R_{00}\right)=1
$$


[23] Using the same approach as in (2), the lowest-order, nondimensional plume density difference (or alternatively plume reduced gravity $\mathrm{g}^{\prime}$ ) is given by

$$
\frac{1}{g^{\prime}} \frac{D g^{\prime}}{D t}=-\frac{W_{e}}{H}=-\frac{\gamma_{1} \Gamma_{1}}{H} U \quad \frac{d \ln \left(g^{\prime}\right)}{d R}=-\frac{\gamma_{1} \Gamma_{1}}{H}
$$

with

$$
g^{\prime}\left(R_{00}\right)=1
$$

We may also combine (4) and (10) to form a conservation equation for density deficit $\mathrm{g}^{\prime} H$ :

$$
\frac{d \ln \left(g^{\prime} H\right)}{d R}=-\left(\frac{d \ln (U)}{d R}+\frac{1}{R}\right)
$$

or

$$
\begin{gathered}
\frac{d \ln \left(U g^{\prime} H\right)}{d R}=-\frac{1}{R} \\
\left.\left(g^{\prime} H\right)\right|_{R_{00}}=1 .
\end{gathered}
$$

[24] The density deficit is useful, because it is the denominator of the internal Froude number $F_{R}$ and is determined only by frontal divergence, the entrainment contributions from (4) and (10) are of opposite sign and cancel. Further analysis requires that the momentum equation (8) be put into a more useful form; using the equations for $g^{\prime}$ and $\mathrm{g}^{\prime} H,(10)$, and (12a)-(12c)

$$
\left(F_{R}^{2}-1\right) \frac{d \ln (U)}{d R}=\frac{1}{R}-\left(F_{R}^{2}-\frac{\operatorname{Pr}}{2}\right) \gamma_{2} \frac{\Gamma(R)}{H},
$$

where Prandtl number $\operatorname{Pr}=\gamma_{1} / \gamma_{2}$.

\section{Results: Model Solutions}

\subsection{Solution Strategy}

[25] Equations (4)-(13) define a lowest-order plume expansion problem with seven unknown functions of $R$ : $H, U, \mathrm{~g}^{\prime}$ (or $\mathrm{g}^{\prime} H$ ), $F_{R}^{2}, \Gamma_{1}, \Gamma_{2}$ and $T$, with parameters, $\gamma_{1}$ and $\gamma_{2}$; several components of the problem are nonlinear. We begin by finding solutions to linear parts of the problem, i.e., for $\mathrm{g}^{\prime}$ (and $\mathrm{g}^{\prime} H$ ) and $F_{R}^{2}$ in terms of $H$ and $U$. We assume that, because entrainment of mass into the plume is the root cause of both thickening and slowing of the plume, $\Gamma_{1}=\Gamma_{2} \equiv \Gamma(R)$. Also, we replace the entrainment coefficient $\gamma_{1}$ using Prandtl number $\operatorname{Pr}$, with $\operatorname{Pr}<1$. Observations can be used to constrain $\gamma_{2} ; \operatorname{Pr}$ will be related to mixing efficiency $E_{F}$.

[26] The remaining equations for $H, U$, and $F_{R}^{2}$ are nonlinear. We consider an approximate analytical solution and compare it to a numerical solution of the nonlinear equations. The solutions discussed below have the following characteristics:

\subsubsection{Analytical Model (Model 1)}

[27] The following two assumptions are made regarding mixing and entrainment: (1) that the depth of the mixing layer between the plume and the underlying water is proportional to $H$ (with an $O(1)$ constant) and (2) that the mixing efficiency $E_{\mathrm{F}}$ is constant. These assumptions allow a reformulation of the problem. While the new equations are still nonlinear, one simplification linearizes the system and allows solutions for $H, U$, and $F_{R}^{2}$ that reproduce most features of numerical solution of the full nonlinear system.

\subsubsection{Numerical Model (Model 2)}

[28] The nonlinear equations for $H, U$, and $F_{R}^{2}$ are solved numerically with three different mixing schemes, including that used in Model 1. These numerical calculations provide both a check on analytical results and the opportunity to examine the consequences of a variety of mixing formulations.

[29] Model 1 was also tested in a preliminary version (not shown) in which $d \mathrm{~g}^{\prime} / d R$ was neglected in the pressure gradient. This test showed that the full pressure gradient variation provides for a more complex variation in $H$ and a more realistic solution. This is logical, since $H / 2 d \mathrm{~g}^{\prime} / d R$ scales as half of $\mathrm{g}^{\prime} d H / d R$.

\subsection{Solutions for Density, Density Deficit, and Froude Number}

[30] It is simple to integrate (10) and (12a)-(12c) to obtain $g^{\prime}$ and $g^{\prime} H$ in terms of $H$ and $U$

$$
\begin{gathered}
g^{\prime}(R)=\operatorname{Exp}\left[-\gamma_{2} \operatorname{Pr} \int_{R_{00}}^{R} \frac{\Gamma(R)}{H} d R^{\prime}\right] \\
\left.\left(g^{\prime} H\right)\right|_{R}=\frac{U_{0}}{U} \frac{R_{00}}{R}=\frac{1}{U} \frac{R_{00}}{R}
\end{gathered}
$$

with $\gamma_{1}=\operatorname{Pr} \gamma_{2}$ and $\Gamma_{1}(R)=\Gamma_{2}(R)=\Gamma(R)$. From (14a), $g^{\prime}$ decreases with $R$, though its variation with $R$ depends on $\Gamma / H$. It is not immediately evident from (14b) whether the mass deficit $g^{\prime} H$ increases or decreases with $R$. Multiplying (14b) by $U$, we see that the density deficit transport $g^{\prime} H U$ varies as $R_{00} / R$

$$
\left.\left(g^{\prime} H U\right)\right|_{R}=\frac{R_{00}}{R} .
$$

[31] Both the mass deficit and its transport are independent of vertical mixing. Although entrainment affects $H, U$ and $g^{\prime}$ individually, its net effect cancels in the product $g^{\prime} H U$. The integral in (14a) is generally intractable, but we can use $(14 \mathrm{~b})$ to determine $\mathrm{g}^{\prime}$ in terms of $H$ and $U$

$$
g^{\prime}=\frac{R_{00}}{R} \frac{1}{H U}
$$

The $R_{00} / R$ factor in $g^{\prime}$ decreases monotonically with $R$, but $(H U)^{-1}$ eventually increases, explaining the slow decrease in $g^{\prime}$ relative to other variables. It is also useful to express the internal Froude number $F_{R}^{2}$ in a form independent of $g^{\prime} H$, using the definition of $F_{R}^{2}$ in (1b) and (14b)

$$
F_{R}^{2}(R)=F_{R 0}^{2} \frac{R}{R_{00}} U^{3} .
$$




\subsection{Frontal Energetics}

[32] We also wish to evaluate frontal energetics from the models. We define, therefore, turbulent kinetic energy production $P$, dissipation $D$, buoyancy flux $B$, and mixing efficiency $E_{\mathrm{F}}=B / D$ in terms of the flux Richardson number $R_{i f}$

$$
\begin{gathered}
P=\gamma_{2} \Gamma \frac{U^{3}}{H}, \\
D=P\left(1-R_{i f}\right), \\
B=\gamma_{1} \Gamma g^{\prime} U=\gamma_{2} \operatorname{Pr} \Gamma g^{\prime} U, \\
E_{F}=-\frac{B}{D}=\frac{\operatorname{Pr} F_{R 0}^{2}}{F_{R}^{2}}=\frac{R_{i f}}{1-R_{i f}} \quad R_{i f}=-\frac{B}{P} .
\end{gathered}
$$

By (20), $E_{\mathrm{F}}$ varies with $F_{R 0}^{2} / F_{R}^{2}$. Thus, for $E_{\mathrm{F}}$ to remain $<1$ (as it should) as the transition point at $R_{F R}$ is approached, $\mathrm{Pr}$ must be spatially variable, an issue addressed in the turbulence closure schemes for both models.

\subsection{Model 1: An Analytical Approach}

[33] Model 1 is an approximate analytical model. For Model 1, we interpret $\Gamma(\mathrm{R})$ as the nondimensional equivalent of a length scale for the depth of the mixing layer, so that $\Gamma(\mathrm{R}) \sim H(\mathrm{R}) . E_{F}$ is assumed constant, and $P r$ is specified in terms of $E_{F}$. With these assumptions, the momentum exchange and entrainment terms are as follows:

$$
\begin{gathered}
\tau_{I}=\gamma_{2} \Gamma(R) U^{2}=\text { const } \gamma_{2} H U^{2} \cong \gamma_{2} H U^{2} \\
W_{E}=\operatorname{Pr} \gamma_{2} \Gamma(R) U=\text { const } E_{F} \frac{F_{R}^{2}}{F_{R 0}^{2}} \gamma_{2} H U \cong \gamma_{2}^{\prime \prime \prime} U H F_{R}^{2} \\
\operatorname{Pr}=E_{F} \frac{F_{R}^{2}}{F_{R 0}^{2}} \quad \gamma_{2}^{\prime \prime \prime}=\text { const } \frac{E_{F}}{F_{R 0}^{2}} \gamma_{2} \cong \frac{E_{F}}{F_{R 0}^{2}} \gamma_{2} .
\end{gathered}
$$

$\operatorname{Pr}$ is now variable, and dependent on the local value of $F_{R}$. Because $F_{R}$ is not a priori specified, it is part of the problem to be solved. That const in (21) is $O(1)$ can be seen from (13), considered at the transition point, $R=R_{T R}$. At $R_{T R}$, the left-hand side of (13) vanishes, and the two terms on the right hand side must balance, allowing evaluation of const. If $E_{F}$ is $O(0.25-0.35)$ for vigorous interfacial mixing [Kay and Jay, 2003], $\operatorname{Pr}>0.25-0.35$ will occur (if at all) only during an initial period of plume motion when $F_{R}^{2}>F_{R 0}^{2}$.

[34] The equations for momentum (13) and mass (6) conservation are, using (21)

$$
\begin{aligned}
& \frac{d \ln (U)}{d R}=-\frac{1}{F_{R}^{2}} \frac{d \ln (H)}{d R}-\beta_{2}, \\
& \frac{d \ln (H)}{d R}=-\frac{1}{R}-\frac{d \ln (U)}{d R}+\gamma_{2}^{\prime \prime \prime} F_{R}^{2},
\end{aligned}
$$

$$
\beta_{2}=\gamma_{2}\left(1-\frac{3}{2} \frac{E_{F}}{F_{R 0}^{2}}\right)
$$

Equation (22) is the sum of (6) and (18), after some rearrangement. We now need a linear evolution equation for $F_{R}^{2}$. We begin from the momentum equation (13) and add $d \ln \left(\mathrm{g}^{\prime} H\right) / d R$ to both sides, and then add (13) and (17) to the result. This operation yields, after application of (21)

$$
\frac{d F_{R}^{2}}{d R}+\left(3 \gamma_{5}-\frac{1}{R}\right) F_{R}^{2}=3 \frac{d \ln (H)}{d R} \quad \gamma_{5}=\gamma_{2}\left(1-2 \frac{E_{F}}{F_{R 0}^{2}}\right)
$$

[35] Equations (22), (23), and (25) have three unknowns $\left(H, U\right.$, and $\left.F_{R}^{2}\right)$. Equation (22) is nonlinear, but one approximation renders it linear, we take $F_{R}^{2}=F_{R m}^{2}$ (in (22) only), where $F_{R m}^{2}$ is a constant to be determined. The solutions are lengthy and given in Appendix A. Also, g' and $D$ are given by (15b) and (18), respectively, and $T(R)$ is integrated numerically from

$$
T(R)=\int_{R_{00}}^{R} U^{-1} d R^{\prime}=\int_{R_{00}}^{R} \frac{1}{\frac{d R^{\prime}}{d t}} d R^{\prime}
$$

[36] Typical dimensional results for Model 1 are provided in Figures 4 and 5, which show the influence on Model 1 of variations in $\gamma_{2}$ and $E_{F}$, respectively. The initial conditions were: $F_{R 0}=1.85, U_{0}=1.85 \mathrm{~m} \mathrm{~s}^{-1}, g^{\prime}\left(R_{0}\right)=0.1 \mathrm{~m} \mathrm{~s}^{-2}$, and $H_{00}=10 \mathrm{~m} . F_{R m}^{2}$ was taken as 1.1 but has surprisingly little influence on the solution. The scaling of $R$ was interpreted such that $R_{0}=1$ at the transition point $R_{T R}$. Then $E_{F 0}=0.27$ and $\gamma_{20}=1.65$ were set such that the middle curve in Figures 4 and 5 produced $F_{R}=1$ at $R=1$. The value of drag coefficient $C_{2}$ equivalent to $\gamma_{20}$ is $C_{2}=6.5 \times 10^{-4}$, which seems plausible [Sorgard et al., 1990].

[37] It is evident from Figures 4 and 5 that $H$ is not necessarily monotonic; there is a sharp initial decrease (due to spreading) in $H$ followed by a slow increase to the transition point, due to entrainment. The initial drop in $H$ forces an initial increase in $F_{R}^{2}$, a feature also shown by most of the numerical schemes below. There is a monotonic decrease in $U$, but the behavior of $\mathrm{g}^{\prime}$ is complex, whether $\mathrm{g}^{\prime}$ increases or decreases with $\gamma_{2}$ depends on $R ; T(R)$ and maximum values of $D$ increase with increased mixing (with $\gamma_{2}$ ) as expected; both of these properties resemble the numerical solutions of Model 2. Over a plausible range of $E_{\mathrm{F}}$, the solutions are not very sensitive to $E_{\mathrm{F}}$, except for $\mathrm{g}^{\prime}$. In contrast, $\gamma_{2}$ is poorly constrained, and $H$ and $F_{R}^{2}$ are sensitive to reasonable variations in $\gamma_{2}$.

\subsection{Model 2: Numerical Solutions for Three Mixing Formulations}

[38] Model 2 obtains numerical solutions by direct numerical integration of the governing equations (2), (7a), (7b), and (10). Solving this system numerically provides a means of evaluating the consistency and accuracy of the assumptions in Model 1 and also permits experimentation with a variety of stress and entrainment parameterizations. 

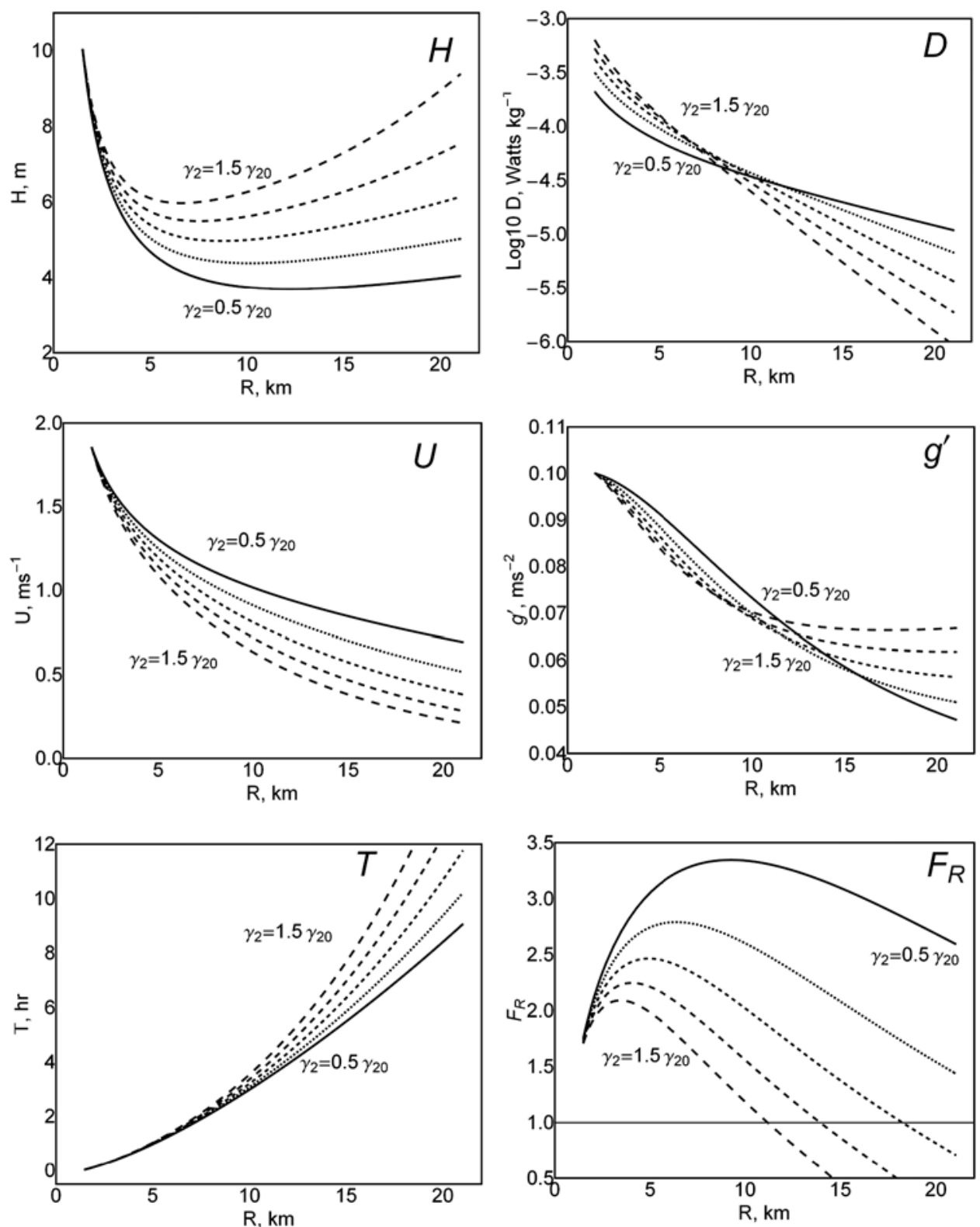

Figure 4. Dimensional results for Model 1 for $E_{F}=0.27$ and five values of $\gamma_{2}=\gamma_{20}\{0.5,0.75,1,1.25$, $1.5\}$, with $\gamma_{20}=1.65$. Shown are $H, D, U, F_{R}, g^{\prime}$, and $T$.

Representation of dissipative processes is, as mentioned above, essential to modeling supercritical plume expansion, and use of a numerical model allows exploration of a variety of turbulence closures, including those that are not analytically tractable.

[39] Several categories of mixing occur in the waters traversed by the tidal plume. One class of mixing processes occurs in the plume frontal zone (or plume frontal "plunge"), and these have been the focus of previous modeling and observational efforts [e.g., Garvine, 1981, 1982; O'Donnell, 1990; O’Donnell et al., 1998, 2008]. A second category of mixing processes occurs behind the front in a region of elevated shear at the plume base [Spahn et al., 2009]. Nonlinear internal waves are released from the front as it becomes subcritical, causing mixing beyond the front [Nash and Moum, 2005; Pan et al., 2007; Pan and Jay, 2009]. Given the high stratification in the plume base, it is likely that internal waves are also involved in mixing behind the plume front, but details are not known. Because of the multiple mixing mechanisms, no single mixing model is likely to be correct for the entire plume liftoff zone, tidal plume and near-field. Our interest here is, however, more limited, we seek a reasonable representation of mixing in the shear layer at the base of the plume, just behind the tidal plume front. This is consistent with the fact that we are not representing the conditions in the actual frontal plunge. Considering only shear mixing at the base of the plume, however, there are still several possible approaches. Our purpose is to examine some of these mixing parameterizations to see if their predictions regarding plume behavior are sufficiently distinctive that one model may be differentiated from another. And if they are different, we seek to determine whether any one model stands out as superior. 

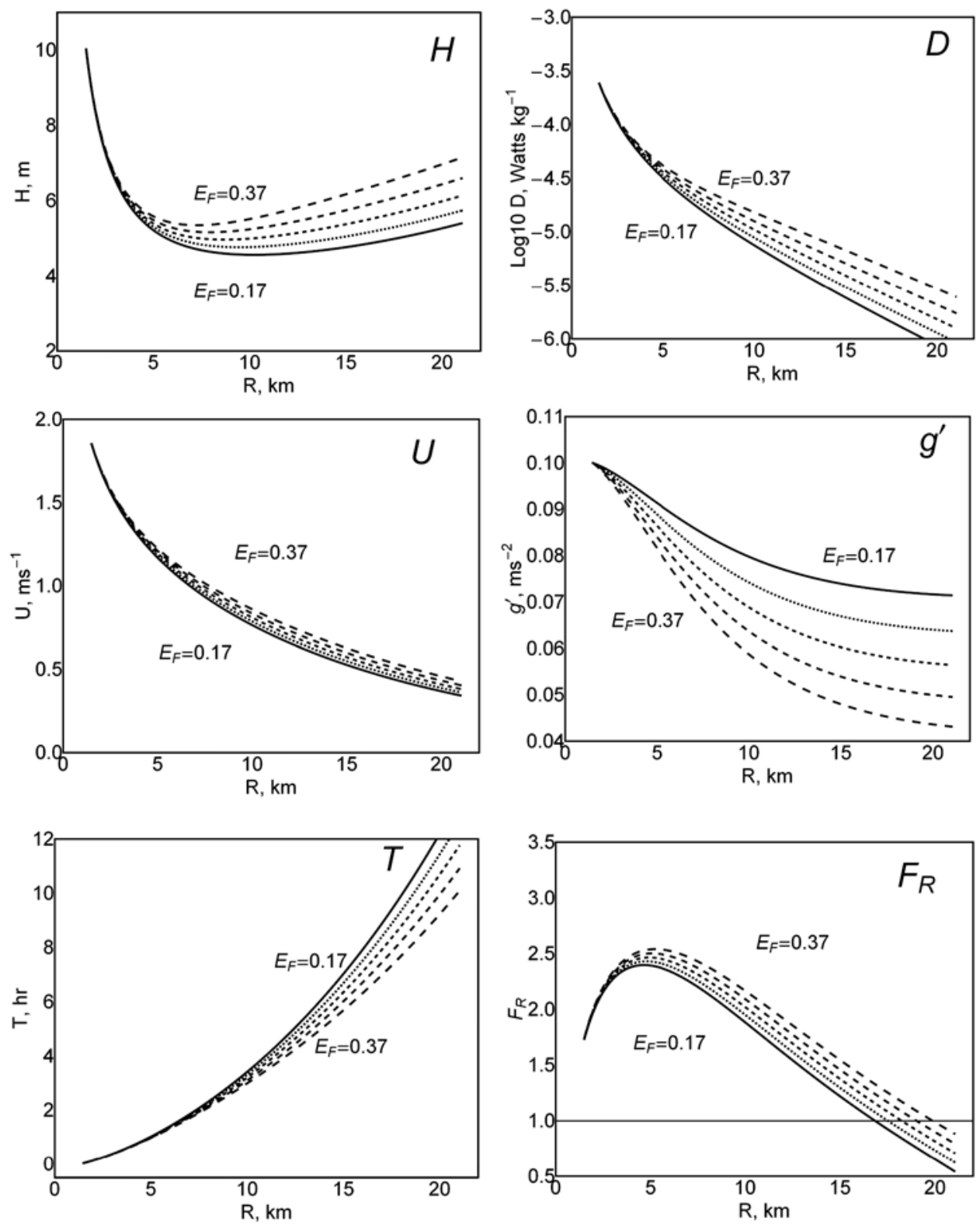

Figure 5. Dimensional results for Model 1 for $\gamma_{2}=1.65$ and five values of $E_{F}=E_{F 0}+\{-0.1,-0.05,0$, $0.05,0.1$, with $E_{F 0}=0.27$. Shown are $H, D, U, g^{\prime}, F_{R}$, and $T$. Only $g^{\prime}$ is more sensitive to $E_{F}$ than $\gamma_{2}$.

[40] We consider three parameterizations for the stress $\hat{\tau}$ and entrainment $\hat{W}_{E}$. Dimensional variables are used, dropping the hats. The mixing schemes will be indicated by a parenthetical superscript on variables, as needed. Common to all models is the assumption of constant mixing efficiency, an assumption also used in Model 1 and supported by numerous observations of stably stratified shear-driven turbulence [e.g., Ivey and Imberger, 1991; Peltier and Caulfield, 2003].

3.5.1. Scheme 1

[41] This approach uses a quadratic stress law with a drag coefficient $\left(\mathrm{C}_{\mathrm{D}}\right)$ having a prescribed spatial variation: $\mathrm{C}_{\mathrm{D}}=$ $\mathrm{C}_{2} \mathrm{H} / \mathrm{H}_{00}$; the dimensional stress is

$$
\tau^{(1)}=C_{2} \frac{H}{H_{00}} U^{2}
$$

In this model, the entrainment $W_{\mathrm{E}}$ is computed from the buoyancy flux $B$ by assuming a constant flux Richardson number ( $R_{i f}$, ratio of buoyancy to production), or equivalently, a constant mixing efficiency $E_{\mathrm{F}}=R_{i f}\left(1-R_{i f}\right)$. Essentially, the assumption here is that the mixing is driven by shear distributed over the entire plume depth $H$, which is also, therefore, the vertical scale for shear. Since plume stratification extends essentially to the free surface, this seems a reasonable approach. Given these assumptions, the dimensional $W_{\mathrm{E}}$ is

$$
W_{E}^{(1)}=C_{D} R_{i f} U=E_{F} C_{2} \frac{H}{H_{00}} \frac{F_{R}^{2}}{F_{R 0}^{2}} U \text {. }
$$

This is the same turbulence closure as used in Model 1. Since $F_{R}^{2}$ is the inverse gradient Richardson number, $R_{i g}^{-1}$, 
Table 2. Parameter Values Used in Model 2

\begin{tabular}{lccc}
\hline Parameter & Value & Range & Reference \\
\hline$R_{i f}$ & 0.2 & $0.1-0.3$ & Piccirillo and Van Atta [1997] \\
$R_{i g c}$ & 0.25 & $0.2-0.3$ & Rohr et al. $[1988]$ \\
$C_{D}$ & $2-3 \times 10^{-4}$ & $1-6 \times 10^{-4}$ & Sorgard et al. [1990] \\
\hline
\end{tabular}

Scheme 1 is also similar to the parameterization first suggested by Ellison and Turner [1959], at least up to a constant.

3.5.2. Scheme 2

[42] This approach is similar to Scheme 1; it uses a quadratic stress law, $\tau^{(2)}=C_{D} U_{F}^{2}$, but $C_{\mathrm{D}}=C_{2}=$ constant. A relationship between the turbulent kinetic energy (TKE) production $P$ and dissipation $D$ is also used; $P$ is given by

$$
P=\tau^{(2)} \frac{U_{F}}{\ell} \quad \ell^{(2)}=H,
$$

where the length scale $\ell$ of the shear is again assumed to be $H$. Entrainment is computed from the turbulent buoyancy flux $B=-\mathrm{g}^{\prime} W_{\mathrm{E}}$ by assuming a constant $R_{i f}=-B / P$; thus

$$
W_{E}^{(1)}=C_{2} R_{i f} U \approx C_{2} E_{F} \frac{F_{R}^{2}}{F_{R 0}^{2}} U
$$

Like Scheme 1, Scheme 2 has the inverse dependence on $R_{\text {ig }}$ suggested by Ellison and Turner [1959].

\subsubsection{Scheme 3}

[43] There is some observational and theoretical support for the assumption (used in both Schemes 1 and 2) that $\ell \sim$ $H$. However, the plume more closely resembles, in its early evolution, a strongly forced estuarine shear layer with constant (critical) $R_{i g}$ [Cudaback and Jay, 2000; Seim and Gregg, 1994]. Under this assumption, the shear is confined to a layer beneath the plume, and the mixing layer thickness 1 is determined from the critical $R_{i g}=R_{i g c}$

$$
\ell^{(3)}=R_{i g c} \frac{U^{2}}{g^{\prime}}=R_{i g c} F_{R}^{2} H .
$$

Thus, Scheme 3 consists of a quadratic stress law with an entrainment formulation based on 1

$$
\begin{gathered}
\tau^{(3)}=C_{D} U^{2} \\
W_{E}^{(3)}=C_{D} \frac{R_{i f}}{R_{i g c}} U,
\end{gathered}
$$

where we have again assumed a constant flux Richardson number $R_{i f}$ and mixing efficiency $E_{F}$. This approach is both conceptually and functionally distinct from the Ellison and Turner [1959] approach in Schemes 1 and 2. The key idea is that the shear is strong and that the turbulence adjusts rapidly enough to maintain the flow in a critical state. Laboratory results suggest the choice of $R_{\text {igc }}$ as $\sim 0.25$ [Rohr et al., 1988; Piccirillo and Van Atta, 1997]. However, internal waves, ubiquitous in the plume but absent in laboratory studies, may influence the turbulence, perhaps modifying $R_{i g c}$ in ways not explored here.
[44] Mixing Schemes 1-3 were incorporated into a numerical model with the following properties. A multistep predictor-corrector scheme is used to integrate (2), (7a), (7b), and (10), with variables evaluated at the central position using the Asselin-Robert filter [Asselin, 1972; Robert, 1966]. Experiments with numerical convergence show that the solution is stable and accurate, except when $F_{R}^{2}$ approaches $F_{R C}^{2}=1$, and the calculation is ended. The values and plausible range of the constants used in Schemes 1-4 are summarized in Table 2. $C_{\mathrm{D}}$ is dependent on environmental conditions and uncertain; it was chosen in the numerical model to yield reasonable agreement with the observed plume propagation distance during greater ebbs. Limited experience suggests that the solutions are highly sensitive to $R_{i f}$ and $R_{i g c}$, but less so to $F_{R}\left(R_{0}\right)$, and $C_{\mathrm{D}}$.

[45] Initial conditions were estimated from observations for 8-9 August 2005 [Moritz et al., 2005]. Five moored tripods were deployed with upward-looking acoustic Doppler current profilers (ADCPs), along with a tethered chain of conductivity-temperature-depth profilers (CTDs), so that simultaneous measurements of velocity and density structure are available at sites in the main navigation channel, $\sim 500 \mathrm{~m}$ apart. $H$ was defined assuming a plume base at the salinity $S=20$ isohaline; $U$ and $g^{\prime}$ were computed as averages above this level. Figure 6 shows the interface data which are the basis for the initial conditions. Fortunately, the results are insensitive to the value of $S$ used to define layers, at least for $S=18-26$. $U$ and $F_{R}^{2}$ are similar for the two lesser ebbs and for the two greater ebbs, but show strong time variations during each tide. The initial conditions are applied at $R_{00}=1500 \mathrm{~m}$, just outside the estuary mouth, $\sim 2 \mathrm{~km}$ from the site of observations. The initial time is referenced to local high water in the estuary, because the onset of plume formation, several $\mathrm{km}$ landward of the observation site, occurs shortly after high water.

[46] We show here Model 2 results for greater ebb (Figure 7). Initial conditions were the same as for Model 1: $U\left(R_{00}\right)=1.85 \mathrm{~m} \mathrm{~s}^{-1}, H\left(R_{00}\right)=10 \mathrm{~m}, g^{\prime}\left(R_{00}\right)=0.1$, and $F_{R}\left(R_{00}\right)=1.85$. All three mixing schemes indicate that the plume propagates between 16 and $23 \mathrm{~km}$ offshore before transitioning to subcritical flow at $F_{R}=1$, generally in accord with observations (Table 1 ) for this tidal range. $H$ initially thins rapidly and then thickens again for all schemes. There are still differences between the schemes, however, emphasizing the sensitivity of plume models to the mixing algorithm used [cf. Hetland, 2005]. Schemes 1 and 2 are generally realistic, but Scheme 3 shows too much thinning at $5-10 \mathrm{~km}$ from the origin. Scheme 3 also differs from the other two for $g^{\prime}, F_{R}, D$ and transition distance (or transition time $\left.T_{T R}\right)$. All schemes show plausible $F_{R}$ histories, but scheme 3 shows a higher maximum value of $F_{R}$ (at $5 \mathrm{~km}$ ), larger values of $g^{\prime}$, and a slower decrease in $D$. Still, predicted values for $D$ are generally similar for Schemes $1-3$.Values of $U$ are, after the first $10 \mathrm{~km}$, mostly within the observed $0.5-0.8 \mathrm{~m} \mathrm{~s}^{-1}$ range. The similar results for $U$, but diverse results for $g^{\prime}$ and $H$, emphasize the importance of the choice of length scale $\ell$. The biggest difference, however, between Scheme 3 and Schemes 1 and 2 lies in the time and location of the transition to subcritical conditions. The transitions time $T_{T R}$ is $\sim 4 \mathrm{hr}$ for Scheme 3 but $6-7$ hours for the other two schemes. These $T_{T R}$ values correspond to a transition radius, $R_{T R}$, of $\sim 16 \mathrm{~km}$ 

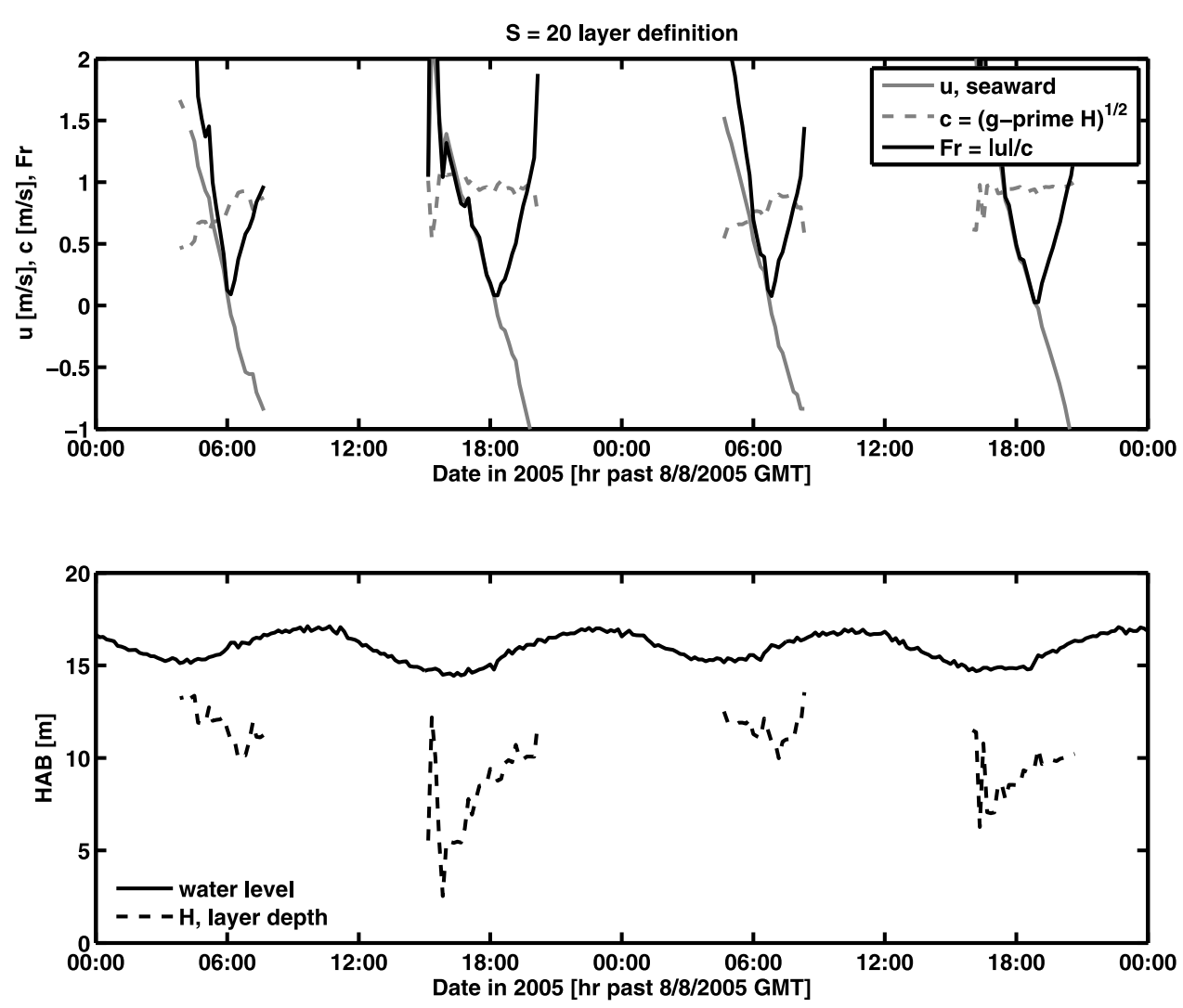

Figure 6. Observations showing plume initial conditions in the MCR area as inferred from a moored upward-looking ADCP and a tethered CTD chain in August 2005. (top) Seaward velocity $(U)$, internal wave speed $\left(c=g^{\prime} H\right)$, and Froude number $\left(F_{R}=U / c\right)$ are shown. (bottom) Water level and depth of the $S=20$ isohaline are shown as height above bottom (HAB). The $S=20$ isohaline is not present when the salt wedge is swept upstream during flood.

for Scheme 3, but $21-23 \mathrm{~km}$ for the other two. The Scheme 3 transition occurs too early, relative to the observations (below).

[47] It is also useful to compare the analytical and numerical models. Results for Model 1 (Figures 4 and 5) and Model 2 (Figure 7) are generally similar, suggesting that linearization of (22) is not fatal to model validity. However, Models 1 and 2 differ in detail, e.g., for $U$ (monotonically decreasing in Figures 4 and 5, but with a maximum just after liftoff for all numerical schemes), $D$ and $g^{\prime}$. Also, Model 1 predicts a slightly larger minimum value of $H$, attainment of minimum $H$ at a larger $R$, slower propagation times, and a smaller transition radius $R_{T R}$. Still, Model 1 results are similar to those for numerical Schemes 1 and 2 in most respects, and the Model 1 predictions of transition timing are actually better than those from the numerical model (below).

[48] It is interesting that a reasonably realistic plume evolution is achieved by both models with minimal tuning of the mixing parameters and without making assumptions about plume frontal jump conditions [cf. Garvine, 1981]. While the details of mixing in the frontal bulge are important to the shape of the frontal plunge and the exact critical value of $F_{R}$, the basic description of plume behavior as a balance between thinning due to radial expansion and thickening due to entrainment is independent of these details, as suggested by (15a). Thus, a model that does not describe frontal behavior in detail can still provide a reasonable representation of tidal plume behavior.

[49] The most similar and most plausible mixing models are Schemes 1 and 2; Scheme 1 is the same as used in the analytical model and bears a strong resemblance to Ellison and Turner [1959]. Both assume a mixing layer scale depth of $H$. Interestingly, this seems to work better than assuming that a constant Richardson number is maintained (Scheme 3 ), though perhaps tuning $R_{i g c}$ would improve the results for Scheme 3.

\section{Discussion}

[50] Direct tests of the frontal models developed here are difficult to obtain. Time histories of frontal properties are needed. Vessel observations (density and velocity sections) are available from RISE (River Influences on Shelf Ecosystems) cruises for a number of plume expansions, but usually with only $1-2$ passes through the front. This does not allow formation of the desired time histories of frontal properties. Also, there is variability around the circumference of the plume related to vorticity dynamics [Jay et al., 2009], so that the appropriate comparison would be to the azimuthally averaged properties; this is impractical with vessel data. Furthermore, many plume frontal crossings occur after the transition to subcritical conditions and do not provide data of interest here. Finally, no RISE data are 

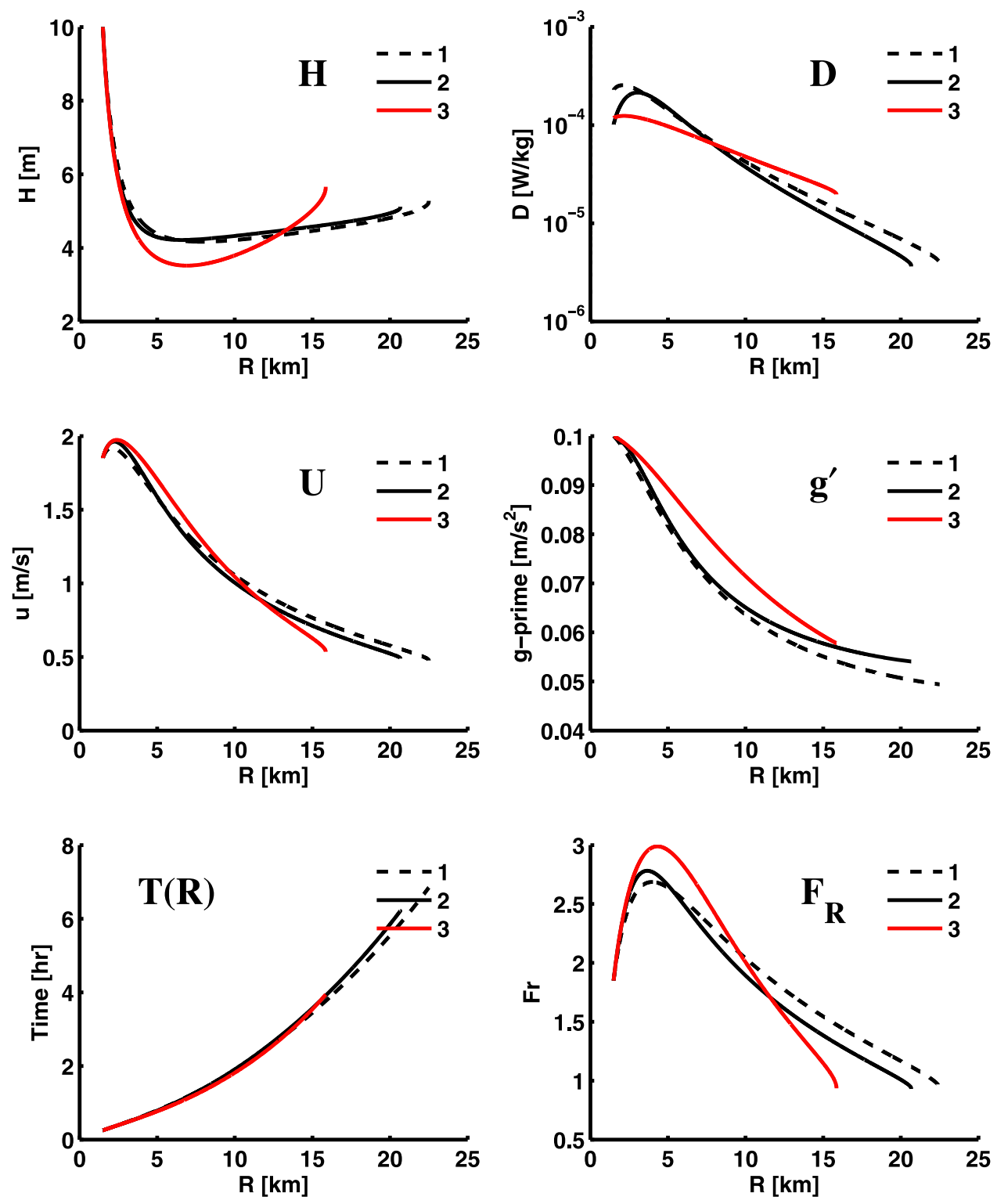

Figure 7. Numerical model results for vertical mixing Schemes 1-3 for greater ebb conditions typical of 8 and 9 August 2005, using the initial condition data based on Figure 6 . Initial conditions are $R_{00}=$ $1.5 \mathrm{~km}, U\left(R_{00}\right)=1.85 \mathrm{~m} \mathrm{~s}^{-1}, H\left(R_{00}\right)=10 \mathrm{~m}$, and $\mathrm{g}_{0}^{\prime}\left(R_{00}\right)=0.1$. Model parameters are as listed in Table 2.

available near the liftoff point to determine initial conditions and the early history of frontal properties, because of difficult sea and vessel traffic conditions.

[51] Overall, the strongest comparison to data is between predicted front travel times and travel times from SAR images (e.g., Figure 1 and Table 1) and ship's radar (Figure 2). Both allow selection of the most appropriate point on the front for estimation of plume radius, and the latter allows, for some periods, direct determination of frontal speeds. Both also allow supercritical fronts to be distinguished from subcritical fronts that are not of interest here.

[52] There are, in comparing theory and data, the following two potentially confounding issues: (1) the different role of tidal currents and river flow in setting the initial Froude number $F_{R 0}=F_{R}\left(R_{00}\right)$ and (2) the effect of coastal currents and wind in altering frontal propagation speed. The above theory incorporates the strength of tidal forcing and river flow together into $F_{R 0} . F_{R 0}$ is the most important forcing variable for all models, but was not be directly observed by RISE. Results from Cudaback and Jay [2000] and other limited observations suggest that river flow and tidal currents have distinct effect on $F_{R 0}$, even though both contribute linearly to the numerator. In particular, we expect increased tidal currents (proportional to tidal range) to increase the initial $H$ but decrease $g^{\prime}$, while increased river flow should increase initial values of both $H$ and $g^{\prime}$. Thus, various combinations of tidal currents and river flow may lead to the same $F_{R 0}$ but different $T(R)$ histories. 

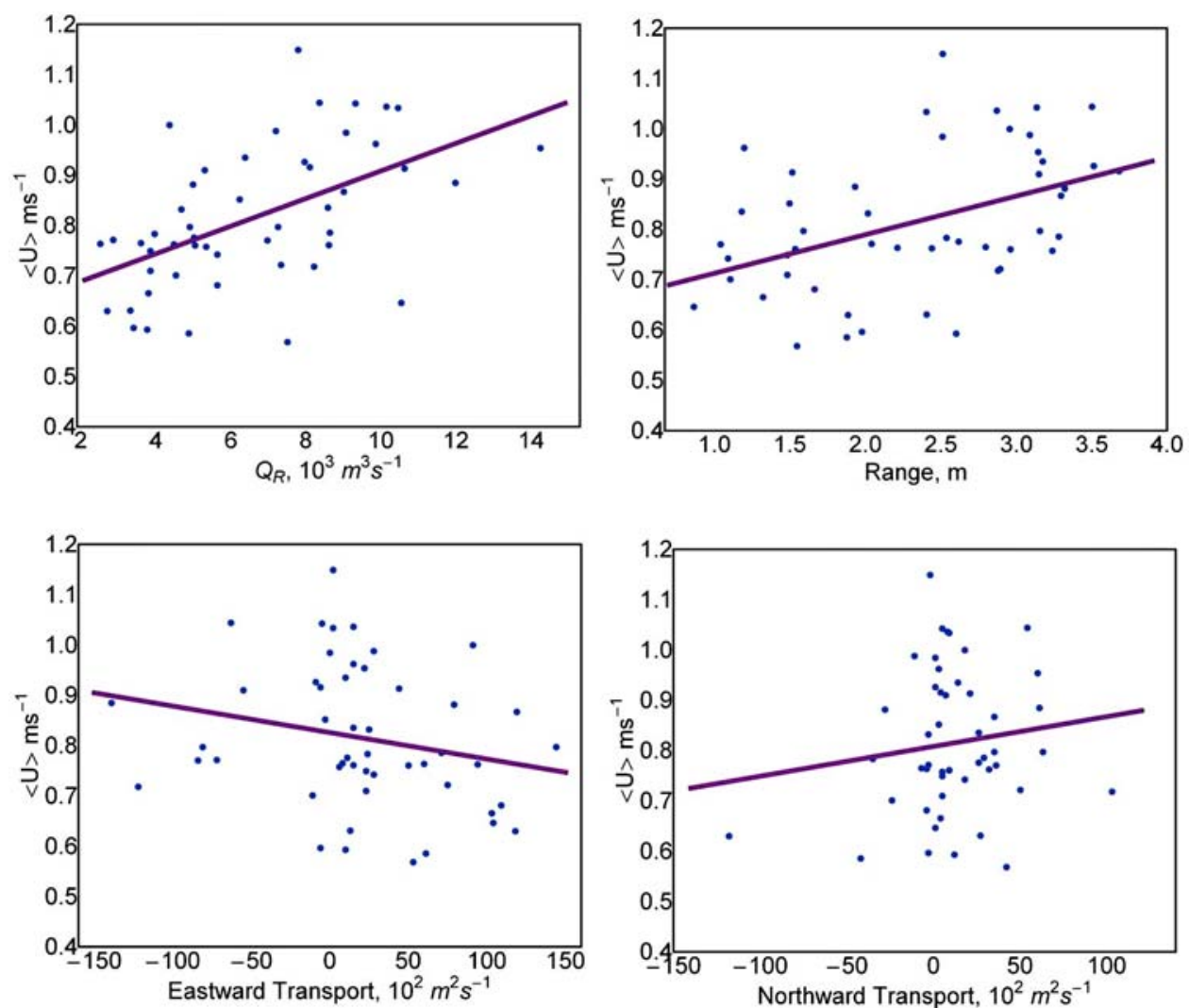

Figure 8. The response of average plume frontal speed $\langle U\rangle=R / T$ from SAR images to forcing by river flow $Q_{R}$, tidal range, offshore transport, and northward transport. $\langle U\rangle$ is distance traveled (from the MCR to the front) divided by elapsed time since plume initiation, 1 hour after high water.

[53] Winds and alongshore currents also affect plume propagation speed through direct advection of the tidal plume and by contributing to mixing. We examine, therefore, the correlations of average plume frontal speed $\langle U\rangle=$ $R / T(R)$ (determined from SAR images) with tidal range in the MCR (http://tidesandcurrents.noaa.gov/tides07/), river flow measured at river $\mathrm{km} 86$ (http://waterdata.usgs.gov/ nwis), and northward and offshore transports at $45^{\circ} \mathrm{N}$, $125^{\circ} \mathrm{W}$ (http://www.cbr.washington.edu/dart/upwell com.html). Figure 8 shows that all parameters are at least weakly correlated with $\langle U\rangle$, but the strongest relationships are with river flow $Q_{R}$ and tidal range, increases in both of which increase $\langle U\rangle$. Offshore transport during upwelling slows the plume slightly. This may occur either because offshore transport is correlated with southward coastal currents, or because offshore currents push the tidal plume offshore into an area of stronger southward advection. Northward transport slightly increases plume frontal speed, likely because of direct northward advection. A multiple linear regression modeling $\langle U\rangle$ in terms of the above four factors has an adjusted $r^{2}=0.46$, only marginally better than the sum of the adjusted $r^{2}$ for linear regressions of $\langle U\rangle$ against $Q_{R}\left(r^{2}=0.27\right)$ and tidal range individually $\left(r^{2}=\right.$ $0.18)$. Nonetheless, addition of each variable improves the regression, and the offshore and northward transports are sufficiently independent that both contribute to the analysis.

[54] In considering Figure 8, certain correlations and sampling biases should be considered. First, longer-lasting plume fronts with a higher initial $F_{R}$ are more likely to be observed, but the longer a plume front has been propagating, the slower it moves. Thus, there is, in principle, a negative correlation between speed and radius, but adding radius to the above multiple linear regression does not explain significant additional variance. Also, frontal asymmetry causes fronts on the north side of the plume to remain supercritical for the longest time, and these fronts are the most likely to be observed. Nonetheless, we use the above regression results to estimate propagation times in the absence of coastal forcing related to upwelling and downwelling.

[55] We compare observed frontal travel time $T(R)$ (from SAR and ship's radar) to predicted $T(R)$, by Model 1 in Figure 9 and by Model 2 (Scheme 2) in Figure 10. Each dot in Figures 9 and 10 represents a travel time from a SAR or ship radar image. The curved lines are predicted travel times for the $F_{R 0}$ indicated. The solid line shows the trend of the SAR data. In constructing Figures 9 and 10, the initial conditions $\mathrm{g}_{0}^{\prime}$ and $H_{00}$ associated with each $F_{R 0}$ were estimated, based on Cudaback and Jay [1996, 2000]. Of interest is the fact that the observed $T(R)$ is nearly linear in $R$ while the models all predict a decrease in speed with $R$. The apparent linearity of the observed $T(R)$ is in part a sampling artifact, different values of $T(R)$ typically represent different initial conditions, with larger $F_{R 0}$ values leading to longer travel times before the transition point is reached. However, Figure 10 shows that the transition points (where $F_{R}=1$ ) also lie along a line, so the almost linear behavior of $T(R)$ versus $R$ is not unexpected. 


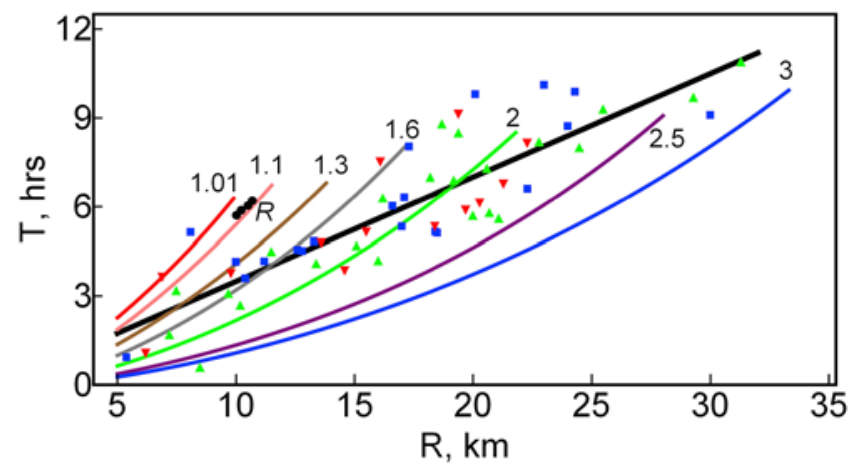

Figure 9. Observed travel time $T(R)$ versus $R$ as extracted from SAR images (upwelling (squares), downwelling (inverted triangles), and neutral (triangles)) and ship's radar (circles). The black line is a best fit to the SAR travel times, $T(R)=0.35 R$ (adjusted $r^{2}=0.76$ ), with $T$ in hours and $R$ in $\mathrm{km}$. Also shown are travel time curves predicted by Model 1 for the initial $F_{R 0}$ values shown, with each curve extending to the transition point where $F_{R}=1$. For Model $1, E_{F}=0.27$ and $\gamma_{2}=1.46-2.06$.

[56] Both Models 1 and 2 provide plausible predictions of frontal trajectories over time, with $F_{R 0}=3$ as the largest forcing value (a conservative choice). It is evident in Figures 9 and 10, however, that predicted travel times fall below the average travel time line (from SAR data) for all initial $F_{R}$ values (Model 2) or the larger initial values (Model 1). Each SAR data point in Figures 9 and 10 represents a front that has not yet decreased to $F_{R}=1$; thus, the regression fit to the SAR data inevitably overestimates average frontal speeds (underestimates travel time $\left.T_{T R}\right)$ to the transition point. This is necessarily the case, because $U$ decreases as the transition point is approached, and the supercritical fronts in SAR images (taken before the front reaches $R_{T R}$ ) do not sample the slowest part of the frontal trajectory. A hypothetical "correct" average travel time curve would, by including the entire trajectory, fall above the SAR regression line. Thus, the predicted travel

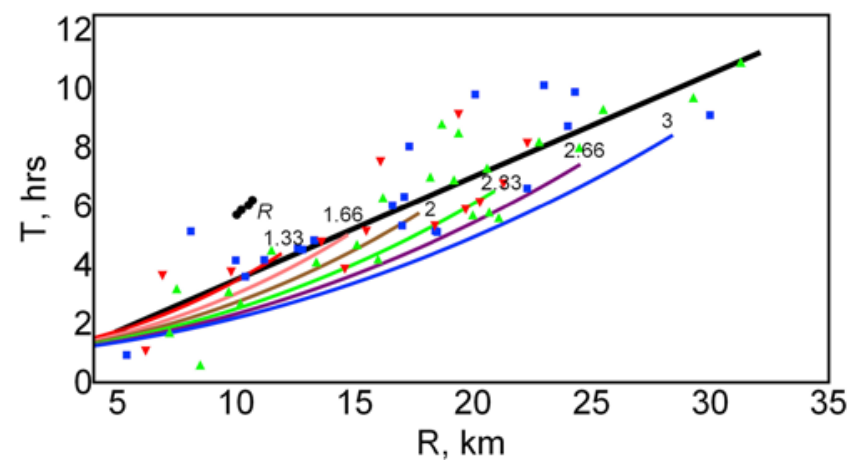

Figure 10. Observed travel time $T(R)$ versus $R$ from SAR images (symbols as in Figure 9). Also shown are travel time curves predicted by Model 2, Scheme 2 for the initial $F_{R}$ values indicated, with each curve extending to the transition point where $F_{R}=1$. The black line is a best fit to the SAR travel times. Other initial conditions and parameters are as in Figure 7.

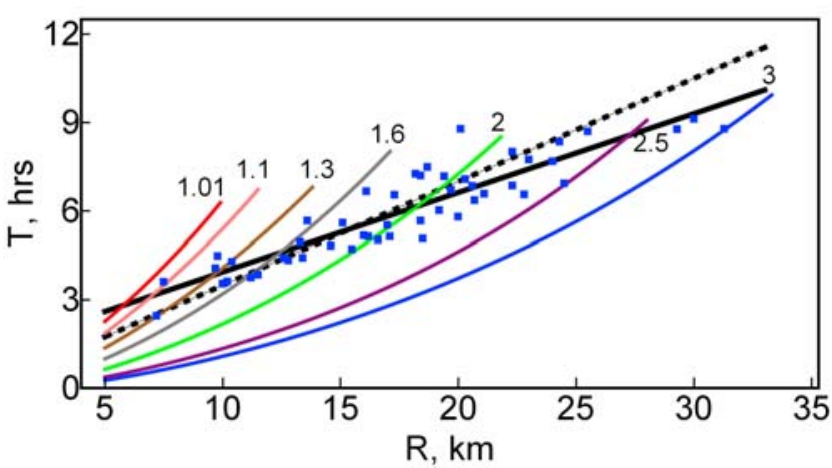

Figure 11a. Predicted frontal travel time $T(R)$ versus $R$ curves for Model 1. Also shown are observed $T(R)$ values from SAR images (squares), with $T(R)$ corrected for upwelling/downwelling effects; see text for details. The solid line is the trend of the corrected $T(R)$ values. The dotted line is the trend of the uncorrected $T(R)$ values from Figure 9.

time lines should cross the regression line as $F_{R}=1$ is approached. We inquire, therefore, why they do not do so in all cases.

[57] Coastal transports influence frontal propagation, particularly for the plume fronts that have traveled the farthest. The multiple linear regression model summarized in Figure 8 has, therefore, been used to hindcast propagation times based only on the influence of $Q_{R}$ and tidal range. This is done by hindcasting frontal speed with the influence of coastal transport removed; i.e., for a hypothetical situation without winds. The results are compared to Models 1 and 2 in Figures 11a and 11b, which show corrected SAR data travel times and predicted travel time curves for Model 1 and for Model (Scheme 2), respectively. There are two straight lines on each plot, the solid line is the trend for the corrected SAR data, while the dotted line is the trend of the uncorrected SAR data (as in Figures 9 and 10). Comparing Figures 9 and 10 to Figures $11 \mathrm{a}$ and $11 \mathrm{~b}$, we see that correction for coastal influences has decreased the slope of the SAR travel times on the $T(R)$ versus $R$ plot; i.e., increased the average speed of the observed plume fronts.

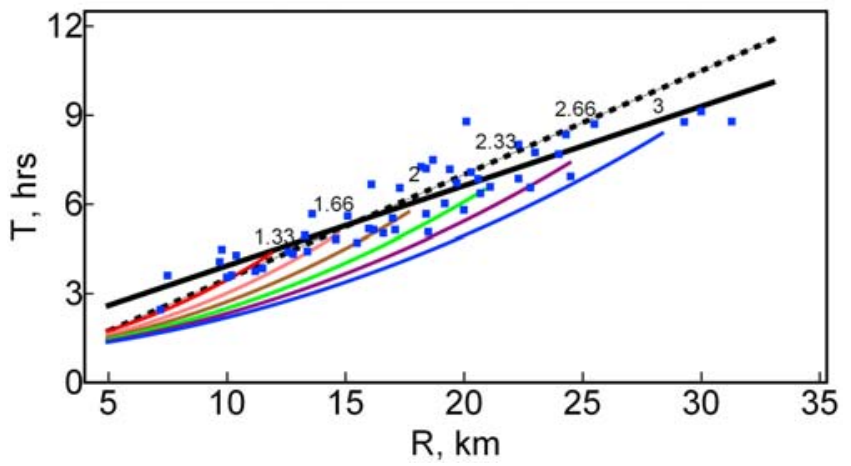

Figure 11b. Predicted frontal travel time $T(R)$ versus $R$ for Model 2, Scheme 2. Also shown are observed $T(R)$ values from SAR images (squares), with $T(R)$ corrected for upwelling/downwelling effects; other details are as in Figure 11a. 
In general, the longest travel distances occur for fronts on the northwest side of the plume during upwelling and weak wind conditions. These fronts are slowed by southward coastal currents, which also provide shear that helps to maintain $F_{R}>1$. Most plumes that have traveled $<12 \mathrm{~km}$ represent downwelling conditions and are accelerated by coastal flows, though some may simply be at a very early stage of propagation. After this correction for coastal influences on the plume, it is evident that Models 1 and 2 provide reasonable predictions for most cases, though Model 2 still predicts travel times that are less than many of the observations.

[58] In summary, Figures 11a and 11b suggest that Model 1 and Scheme 2 of Model 2 predict plausible plume front travel times, in terms of $T_{T R}$ values. Model 1 uses a mixing model that is essentially the same as Scheme 1 for Model 2, and Schemes 1 and 2 for the Model 2 are also quite similar. What schemes 1 and 2 have in common is an assumption that the shear length scale is directly proportion to plume thickness, which, consequently, results in an entrainment scheme with inverse $R_{i g}$ dependence [Ellison and Turner, 1959]. The performance of Scheme 3, which sets the mixing scale length by maintaining a specified critical gradient Richardson number $R_{i g c}$, is also generally similar to Schemes 1 and 2 with respect to velocity $U$ and travel time $T(R)$. Scheme 3 differs, however, from Schemes 1 and 2 with respect to frontal depth $H$, density $g^{\prime}$, and transition time $T_{T R}$. While we are not able to provide a conclusive comparison to data for these parameters, it appears that Scheme 3 predicts too much thinning of the plume in the early stages of propagation, leading to a premature transition to subcritical conditions.

\section{Conclusions}

[59] This contribution has analyzed the initial motion of the tidally pulsed plume emanating from the Columbia River mouth. Following Rudnick and Davis [1988], Lagrangian frontal equations were used, simplifying the analysis of supercritical frontal propagation. The analysis is applicable to the tidal plume front, which bounds the plume near-field waters that have been in the coastal ocean less than $\sim 12$ hours. This time period is critical, because it is during the initial interaction with coastal water that the most rapid changes occur to the plume. After the tidal plume front slows to a subcritical state, vertical mixing is reduced and the tidal plume merges into the rest of the plume near-field.

[60] Model results suggest that the Lagrangian framework is useful in that the equations are subject to analytical, though still approximate, solutions for the plume frontal variables: depth $H$, speed $U$, density deficit $\mathrm{g}^{\prime}$, and frontal Froude number $F_{R}^{2}$. It is important that $F_{R}^{2}$ not be constrained to have some simple form, even though this complicates solution of the Lagrangian equations by adding another unknown. Early versions of the analytical model (not shown) that did prescribe $F_{R}^{2}$ did not perform as well as Model 1 (the analytical model finally implemented) or Model 2 (the numerical model implemented with three turbulence closures).

[61] The approximate, analytical solution (Model 1) avoids any assumption regarding the form of $F_{R}^{2}$, but does assume a spatially constant mixing efficiency and that mixing layer thickness is proportional to $H$. Model 1 predicts realistic frontal speeds, when compared to travel time data from ship's radar and SAR images.

[62] The Lagrangian frontal propagation equations can also be solved numerically (Model 2). We have done so with three mixing schemes, the first of which mimics Model 1, without the approximations needed to obtain analytical results. Two of the three mixing schemes tested produce similar results. Both assumed a specific formulation for a vertical length scale over which vertical mixing occurs, as in Model 1 and Ellison and Turner [1959]. Predicted $F_{R}^{2}$ variations and travel times for the two more realistic mixing schemes are also quite similar to Model 1.

[63] It is important to include both the barotropic and baroclinic components of the pressure gradient, which is formulated using an isostatic assumption for the surface slope. The baroclinic pressure gradient component, related to the radial density variation of the plume front, is often not included in analytical analyses of plume dynamics.

\section{Appendix A}

[64] Here, we set out the solutions for Model 1. Model 1 has three primary unknowns: $F_{R}^{2}, H$ and $U$, which are specified by solution of (22), (23), and (25). $F_{R}^{2}$ from (25) is

$$
\begin{aligned}
F_{R}^{2}= & e^{-f_{1}(R)}\left(\left(R \text { const }_{1}-\frac{3 F_{R m}^{2}}{1+F_{R m}^{2}} e^{f_{1}(R)}\right)\right. \\
& \left.-3 R \frac{F_{R m}^{2}}{\left(1+F_{R m}^{2}\right)^{2}} f_{2} \operatorname{ExpInt}\left(f_{1}(R)\right)\right) \\
f_{1}(R)= & \frac{3\left(F_{R m}^{2}\left(\gamma_{2}^{\prime \prime \prime}+\gamma_{5}\right)+\gamma_{5}\right)}{1+F_{R m}^{2}} R \\
f_{2}= & \left(\left(1+F_{R m}^{2}\right) \beta_{2}-3\left(\gamma_{5}+\left(\gamma_{2}^{\prime \prime \prime}+\gamma_{5}\right) F_{R m}^{2}\right)\right) \\
\gamma_{5}= & 1-2 \frac{E_{F}}{F_{R 0}^{2}}
\end{aligned}
$$

where

$$
\operatorname{ExpInt}(z)=-\int_{-z}^{\infty} \frac{e^{-z^{\prime}}}{z^{\prime}} d z^{\prime}
$$

Integration constant const $_{1}$ is

$$
\begin{aligned}
\text { const }_{1}= & \frac{e^{-f_{1}\left(R_{00}\right)}}{R_{00}}\left(F_{R 0}^{2}+\frac{3 F_{R m}^{2}}{1+F_{R m}^{2}}\right. \\
& \left.+\frac{3 F_{R m}^{2}}{\left(1+F_{R m}^{2}\right)^{2}} R_{00} e^{-f_{1}\left(R_{00}\right)} f_{2} \operatorname{ExpInt}\left(f_{1}\left(R_{00}\right)\right)\right) .
\end{aligned}
$$

$H$ from (23) is given by

$$
H=\text { const }_{2} e^{f_{4}(R)} e^{-\frac{e^{-f_{1}(R)} f_{5}(R)}{9 / 3 a} \text { const }_{1}} e^{\frac{\gamma_{2}^{\prime \prime \prime} F_{R m}^{2} f_{2} f_{5}(R)}{\left(1+F_{R m}^{2}\right)^{2} / 3 / 3 a} e^{-f_{1}(R)} \operatorname{ExpInt}\left(f_{1}(R)\right)} R^{-\frac{f_{6}}{3 / 3 a}},
$$


with

$$
\begin{aligned}
& f_{3 a}=\frac{\left(F_{R m}^{2}\left(\gamma_{2}^{\prime \prime \prime}+\gamma_{5}\right)+\gamma_{5}\right)^{2}}{F_{R m}^{2}} \\
& f_{4}(R)=\beta_{2} \gamma_{2}^{(5)}\left(\gamma_{5}+F_{R m}^{2}\left(\gamma_{2}^{\prime \prime \prime}+\gamma_{5}\right)\right) R \\
& f_{5}(R)=\gamma_{2}^{\prime \prime \prime}\left(1+3 R \gamma_{5}+F_{R m}^{2}\left(1+3 R\left(\gamma_{2}^{\prime \prime \prime}+\gamma_{5}\right)\right)\right) . \\
& f_{6}=3 \gamma_{5}^{2}+F_{R m}^{2}\left(\beta_{2} \gamma_{2}^{\prime \prime \prime}+3 \gamma_{2}^{(5)}\left(\gamma_{2}^{\prime \prime \prime}+\gamma_{5}\right)\right)
\end{aligned}
$$

Integration constant const $_{2}$ is

$$
\begin{aligned}
& \text { const }_{2}=e^{-\frac{f_{4}\left(R_{00}\right)}{f_{3 a}}} e^{e^{-f_{1}\left(R_{00}\right)_{f_{5}}\left(R_{00}\right)} \text { const }_{1}} \\
& \cdot e^{-\frac{\gamma_{2}^{\prime \prime \prime} F_{R m}^{2}}{\left(1+F_{R m}^{2}\right)^{2}} \frac{f_{2} f_{5}\left(R_{00}\right)}{3 / 3 a} e^{-f_{1}\left(R_{00}\right)} \operatorname{ExpInt}\left(f_{1}\left(R_{00}\right)\right)} R_{00}^{\frac{f_{6}}{3 f_{3 a}}} .
\end{aligned}
$$

$U$ from (22) is given by

$$
\begin{aligned}
U_{F}= & \operatorname{const}_{3} e^{-\frac{\gamma_{2}^{\prime \prime \prime}+\gamma_{5}}{\gamma_{5}} \frac{f_{4}(R)}{f_{3 a}}} e^{-\frac{e^{-f_{1}(R)} \frac{f_{5}(R)}{9 f_{3 b}} \text { const }_{1}}{}} \\
& \cdot e^{\frac{\gamma_{2}^{\prime \prime \prime} F_{R m}^{2}}{\left(1+F_{R m}^{2}\right)^{2}} \frac{f_{2} f_{5}(R)}{3 / 3 b} e^{-f_{1}(R)}} \operatorname{ExpInt(f_{1}(R))} R^{-\frac{f_{6}}{3 / 3 b}},
\end{aligned}
$$

with

$$
f_{3 b}=\left(F_{R m}^{2}\left(\gamma_{2}^{\prime \prime \prime}+\gamma_{5}\right)+\gamma_{5}\right)^{2}
$$

Integration constant const $_{3}$ is

$$
\begin{aligned}
\text { const }_{3}= & e^{\frac{\gamma_{2}^{\prime \prime \prime}+\gamma_{5} f_{4}\left(R_{00}\right)}{\gamma_{3}}} e^{\frac{e^{-f_{1}\left(R_{00}\right)_{f_{5}}\left(R_{00}\right)}}{9 f_{3 b}} \text { const }_{1}} \\
& \cdot e^{-\frac{\gamma_{2}^{\prime \prime \prime} F_{R m}^{2}}{\left(1+F_{R m}^{2}\right)^{2}} \frac{f_{2} f_{5}\left(R_{00}\right)}{3 / 3 b} e^{-f_{1}\left(R_{00}\right)} \operatorname{ExpInt}\left(f_{1}\left(R_{00}\right)\right)} R_{00}^{\frac{f_{6}}{3 / 3 b}} .
\end{aligned}
$$

These values were derived using the symbolic algebra capabilities and differential equation solver in Mathematica ${ }^{\mathbb{B}}$.

[65] Acknowledgments. This research was supported by the National Science Foundation project RISE (River Influences on Shelf Ecosystems; OCE 0239072). The SAR images were provided by Comprehensive Large Array-data Stewardship System (CLASS) of National Oceanic and Atmospheric Administration (NOAA). Thanks to Keith Leffler for preparing Figure 2.

\section{References}

Asselin, R. A. (1972), Frequency filter for time integrations, Mon. Weather Rev., 100, 487-490, doi:10.1175/1520-0493(1972)100<0487: FFFTI $>2.3 . \mathrm{CO} ; 2$.

Barnes, C. A., C. Duxbury, and B.-A. Morse (1972), Circulation and selected properties of the Columbia River plume at sea, in The Columbia River Estuary and Adjacent Ocean Waters, edited by A. T. Pruter and D. L. Alverson, pp. 41-80, Univ. of Wash., Seattle, Wash.

Benjamin, T. B. (1968), Gravity currents and related phenomena, J. Fluid Mech., 31, 209-243, doi:10.1017/S0022112068000133.

Bottom, D. L., C. A. Simenstad, J. Burke, A. M. Baptista, D. A. Jay, K. K. Jones, E. Casillas, and M. H. Schiewe (2005), Salmon at river's end: The role of the estuary in the decline and recovery of Columbia River salmon, NOAA Tech. Memo. NMFS-NWFSC-68, 246 pp., Northwest Fish. Sci. Cent., Seattle, Wash.

Britter, R. E., and J. E. Simpson (1978), Experiments on the dynamics of a gravity current head, J. Fluid Mech., 88, 223-240, doi:10.1017/ S0022112078002074.

Chu, V. H., and R. E. Baddour (1984), Turbulent gravity-stratified shear flows, J. Fluid Mech., 138, 353-378, doi:10.1017/S002211208400015X.
Chu, V. H., and G. H. Jirka (1986), Surface buoyant jets and plumes, in Encyclopedia of Fluid Mechanics, edited by N. Cheremisinoff, pp. 1053-1083, Gulf, Houston, Tex.

Cudaback, C. N., and D. A. Jay (1996), Buoyant plume formation at the mouth of the Columbia River-an example of internal hydraulic control?, in Buoyancy Effects on Coastal and Estuarine Dynamics, Coastal Estuarine Stud. Ser., vol. 53, edited by D. G. Aubrey and C. T. Friedrichs, pp. 139-154, AGU, Washington, D. C.

Cudaback, C. N., and D. A. Jay (2000), Tidal asymmetry in an estuarine pycnocline: 1. Depth and thickness, J. Geophys. Res., 105, 26,23726,252, doi:10.1029/2000JC900135.

Ellison, T. H., and J. S. Turner (1959), Turbulent entrainment in stratified flows, J. Fluid Mech., 6, 423-448.

Fong, D. A., and W. R. Geyer (2002), The alongshore transport of freshwater in a surface-trapped river plume, J. Phys. Oceanogr., 32, 957-972, doi:10.1175/1520-0485(2002)032<0957:TATOFI >2.0.CO;2.

Garvine, R. W. (1981), Frontal jump conditions for models of shallow buoyant surface layer hydrodynamics, Tellus, 33, 301-312.

Garvine, R. W. (1982), A steady-state model for buoyant surface plume hydrodynamics in coastal waters, Tellus, 34, 293-306.

Garvine, R. W. (1987), Estuary plumes and fronts in shelf waters: A layer model, J. Phys. Oceanogr., 17, 1877-1896, doi:10.1175/15200485(1987)017<1877:EPAFIS $>2.0$.CO;2.

Garvine, R. W., and J. Monk (1974), Frontal structure of a river plume, J. Geophys. Res., 79, 2251-2259, doi:10.1029/JC079i015p02251.

Gustafson, R. G., R. S. Waples, J. M. Myers, L. A. Weitkamp, G. J. Bryant, O. W. Johnson, and J. J. Hard (2007), Pacific salmon extinctions: Quantifying lost and remaining diversity, Conserv. Biol., 21, 1009-1020, doi:10.1111/j.1523-1739.2007.00693.x.

Hetland, R. D. (2005), Relating river plume structure to vertical mixing, J. Phys. Oceanogr., 35, 1667-1688, doi:10.1175/JPO2774.1.

Hetland, R. D., and D. MacDonald (2008), Spreading in the near-field Merrimack River plume, Ocean Modell., 21, 12-21.

Hickey, B. M., L. J. Pietrafesa, D. A. Jay, and W. C. Boicourt (1998), The Columbia River Plume Study: Subtidal variability in the velocity and salinity fields, J. Geophys. Res., 103, 10,339-10,368, doi:10.1029/ 97JC03290.

Hickey, B. M., S. L. Geier, N. B. Kachel, and A. MacFadyen (2005), A bi-directional river plume: The Columbia in summer, Cont. Shelf Res., 25, 1631-1656, doi:10.1016/j.csr.2005.04.010.

Hickey, B. M., et al. (2009), River influences on shelf ecosystems: Introduction and synthesis, J. Geophys. Res., doi:10.1029/2009JC005452, in press.

Horner-Devine, A. R. (2009), The bulge circulation in the Columbia River plume, Cont. Shelf Res., 29, 234-251, doi:10.1016/ j.csr.2007.12.012.

Horner-Devine, A. R., D. A. Jay, P. M. Orton, and E. Y. Spahn (2009), A conceptual model of the strongly tidal Columbia River plume, J. Mar Syst., 78, 460-475, doi:10.1016/j.jmarsys.2008.11.025.

Ingram, G. R. (1981), Characteristics of the Great Whale River plume, J. Geophys. Res., 86, 2017-2023, doi:10.1029/JC086iC03p02017.

Ivey, G. N., and J. Imberger (1991), On the nature of turbulence in a stratified fluid. Part II: Application to lakes, J. Phys. Oceanogr., 21, 659-680, doi:10.1175/1520-0485(1991)021<0650:OTNOTI $>2.0$.CO;2.

Jay, D. A., J. Pan, P. M. Orton, and A. Horner-Devine (2009), Asymmetry of tidal plume fronts in an eastern boundary current regime, J. Mar. Syst., 78, 442-459, doi:10.1016/j.jmarsys.2008.11.015.

Kay, D. J., and D. A. Jay (2003), Interfacial mixing in a highly stratified estuary: 1. Characteristics of mixing, J. Geophys. Res., 108(C3), 3072, doi:10.1029/2000JC000252.

Luketina, D. A., and J. Imberger (1987), Characteristics of a surface buoyant jet, J. Geophys. Res., 92, 5435-5447, doi:10.1029/JC092iC05p05435.

Luketina, D. A., and J. Imberger (1989), Turbulence and entrainment in a buoyant surface plume, J. Geophys. Res., 94(12), 619-636.

MacDonald, D. G., and W. R. Geyer (2004), Turbulent energy production and entrainment at a highly stratified estuarine front, J. Geophys. Res., 109, C05004, doi:10.1029/2003JC002094

Moritz, H. R., G. R. Gelfenbaum, and P. Ruggiero (2005), Morphological implications of oceanographic measurements acquired along a megatransect at the mouth of the Columbia River, USA, Eos Trans. $A G U$, 86(52), Fall Meet. Suppl., Abstract OS23A-1534.

Nash, J. D., and J. N. Moum (2005), River plumes as a source of largeamplitude internal waves in the coastal ocean, Nature, 437, 400-403, doi:10.1038/nature03936.

Nash, J. D., L. Kilcher, and J. N. Moum (2009), Structure and composition of a strongly stratified, tidally pulsed river plume, J. Geophys. Res., 114, C00B12, doi:10.1029/2008JC005036.

O'Donnell, J. (1990), The formation and fate of a river plumes: Numerical model, J. Phys. Oceanogr., 20, 551-569, doi:10.1175/15200485(1990)020<0551:TFAFOA $>2.0 . \mathrm{CO} ; 2$. 
O’Donnell, J., G. O. Marmorino, and C. L. Trump (1998), Convergence and downwelling at a river plume front, J. Phys. Oceanogr., 28, 1481-1495, doi:10.1175/1520-0485(1998)028<1481:CADAAR >2.0.CO;2.

O'Donnell, J., S. G. Ackleson, and E. R. Levine (2008), On the spatial scales of a river plume, J. Geophys. Res., 113, C04017, doi:10.1029/ 2007JC004440.

Orton, P. M., and D. A. Jay (2005), Observations at the tidal plume front of a high-volume river outflow, Geophys. Res. Lett., 32, L11605, doi:10.1029/2005GL022372.

Pan, J., and D. A. Jay (2009), Dynamics characteristics and horizontal transport of large amplitude internal solitons generated at the Columbia River plume front, Cont. Shelf Res., 29, 252-262, doi:10.1016/ j.csr.2008.01.002.

Pan, J., D. A. Jay, and P. M. Orton (2007), Analyses of internal solitary waves generated at the Columbia River plume front using SAR imagery, J. Geophys. Res., 112, C07014, doi:10.1029/2006JC003688.

Peltier, W. R., and C. P. Caulfield (2003), Mixing efficiency in stratified shear flows, Annu. Rev. Fluid Mech., 35, 135-167, doi:10.1146/annurev. fluid.35.101101.161144.

Piccirillo, P., and C. W. Van Atta (1997), The evolution of a uniformly sheared thermally stratified turbulent flow, J. Fluid Mech., 334, 61-86, doi:10.1017/S002211209600434X.

Pritchard, M., and D. A. Huntley (2006), A simplified energy and mixing budget for a small river plume discharge, J. Geophys. Res., 111, C03019, doi:10.1029/2005JC002984.

Robert, A. J. (1966), The integration of a low order spectral form of the primitive meteorological equations, J. Meteorol. Soc. Jpn., 44, 237-244.
Røed, L. P. (1997), Energy diagnostics in a 1 1/2-layer, non-isopycnal model, J. Phys. Oceanogr., 27, 1472-1476, doi:10.1175/15200485(1997)027<1472:EDIALN>2.0.CO;2.

Rohr, J. J., E. C. Itsweire, K. N. Hellland, and C. W. Van Atta (1988), Growth and decay of turbulence in a stably stratified shear flow, J. Fluid Mech., 195, 77-111, doi:10.1017/S0022112088002332.

Rudnick, D. L., and R. E. Davis (1988), Frontogenesis in mixed layers, J. Phys. Oceanogr., 18, 434-457, doi:10.1175/1520-0485(1988)018 $<0434$ :FIML $>2.0 . \mathrm{CO} ; 2$.

Seim, H., and M. C. Gregg (1994), Detailed observations of a naturally occurring shear instability, J. Geophys. Res., 99, 10,049-10,073, doi:10.1029/94JC00168.

Sorgard, E., T. Martinsen, and E. Aas (1990), Drag coefficient at a stationary salt wedge, J. Geophys. Res., 95, 7337-7345, doi:10.1029/ JC095iC05p07337.

Spahn, E. Y., A. R. Horner-Devine, J. Nash, D. A. Jay, and L. Kilcher (2009), Particle resuspension in the Columbia River plume near field, J. Geophys. Res., 114, C00B14, doi:10.1029/2008JC004986.

Thomas, A. C., and R. A. Weatherbee (2006), Satellite-measured temporal variability of the Columbia River plume, Remote Sens. Environ., 100, 167-178, doi:10.1016/j.rse.2005.10.018.

Yankovsky, A. E., and D. C. Chapman (1997), A simple theory for the fate of buoyant coastal discharges, J. Phys. Oceanogr., 27, 1386-1401, doi:10.1175/1520-0485(1997)027<1386:ASTFTF>2.0.CO;2.

D. A. Jay, J. Pan, and E. D. Zaron, Department of Civil and Environmental Engineering, Portland State University, PO Box 751, Portland, OR 97207, USA. (djay@cecs.pdx.edu; panj@cecs.pdx.edu; zaron@cecs.pdx.edu) 